\title{
Modelling of flowslides and debris avalanches in natural and engineered slopes: a review
}

\author{
Sabatino Cuomo(i)
}

\begin{abstract}
Background: The landslides of the flow-type are dangerous and also challenging to study. A wide literature has been investigating the principal mechanisms governing each stage in which these phenomena can be ideally subdivided: failure, post-failure and propagation. However, holistic contributions and general overviews are very rare. In addition, a number of numerical methods have been issued and validated so that new chances exist to efficiently model those threats. The paper focuses on two classes of rainfall-induced landslides of the flow-type, namely debris flows and debris avalanches. The principal numerical methods are reviewed for modelling the landslide initiation and propagation and are later used for analyzing a series of benchmark slopes and real case histories which are successfully simulated.

Results: The rainfall from ground surface and water spring from the bedrock are key factors for slope instability. Pore water pressure plays a relevant role also during the propagation stage. The entrainment of further material makes the propagation patterns complex due to lateral spreading and slow-down of the front of flows. It is shown that the used models are capable to provide useful indications even for combined channelized and unchannelized flows.

Conclusions: Notwithstanding the complexity of flow-like landslides and the related challenges in modelling, the understanding and forecasting of such natural hazards is achievable with a satisfactory confidence. Among the key factors, rainfall, pore water pressure and bed entrainment deserves a special attention. Further improvements are expectable as the numerical models are becoming more efficient. Thus, more accurate descriptions of local effects will be possible and also additional mechanisms will be eventually analysed.
\end{abstract}

Keywords: Rainfall, Landslide, Flow, Modelling, Countermeasure

\section{Introduction}

The geomechanical modelling of hillslope instability phenomena has been posing challenges to scientists for many decades. Indeed, most of the difficulties arise from the significant kinematic differences between the different stages of a landslide namely failure, post-failure and propagation.

Hillslopes generally undergo small deformations in the so-called pre-failure stage. The failure stage (Cuomo, 2006), in turn, may consist in the formation of a continuous shear surface through the entire soil mass

Correspondence: scuomo@unisa.it

Geotechnical Engineering Group (GEG), University of Salerno, Via Giovanni Paolo II, 13284084 Fisciano, Italy
(Leroueil, 2001) where large soil deformations mainly concentrate and it is usually referred as "localized" failure. In some cases, plastic strains can affect large amount of soil originating a so-called "diffuse" failure (Darve and Laoufa, 2000; Pastor et al., 2004). In both cases, the failure stage leads to large displacements.

The post-failure stage is characterized by the rapid generation of large plastic strains and the consequent sudden acceleration of the failed soil mass (Hungr, 2004) and it discriminates among different types of phenomena (Cascini et al., 2010), i.e. slide, slides turning into flows and flowslides. A slide occurs when limit equilibrium condition is gradually reached along a shear zone so that unbalance between driving and resisting forces is moderate and the unstable mass does not accelerate 
abruptly. The transition from a slide to a flow is typically caused by cascading effects of local failure and variation in slope geometry. The initial stress state is changed abruptly and no chance exists for the slope to be stable anymore. While the previous two categories are independent on the soil constitutive behaviour, flowslides are related to static liquefaction (Sladen et al., 1985; Chu et al., 2003) or soil mechanical instability phenomena (Darve and Laouafa, 2000), which are both even challenging to be modelled. It is important noting that large acceleration of the failed mass are typical of "flows" and "flowslides", as labelled later on.

The propagation stage includes the movement of the failed mass from the source to the deposition area, where a new equilibrium configuration is possible and depends on both the amount of moving material and slope geometry. In the case of slides, the failed mass experiences displacements of one or two orders of magnitude lower than the landslide source dimensions. Conversely, for flows and flowslides the run-out distances are up to two orders of magnitude higher than the length of the landslide source (Cascini et al., 2011a, 2011b, 2016, 2019).

These mentioned differences are even more exacerbated in the case of the so-called flow-like landslides, which in most of the cases originate from shallow landslides. Two categories deserve special attention: debris flows and debris avalanches. Debris Flows (DF) propagate in V-shaped channels, where large amount of water is available during heavy rainstorms so that the propagating mass may fluidize before stopping (Cascini et al., 2014). Relevant examples of DFs are available from British Columbia (Canada), Cina, France, Hong Kong, Japan, Oregon (USA) and Switzerland (Braun et al., 2017, 2018; Iverson, 1997; Pastor et al., 2007a, b; Crosta et al., 2009; Hungr and McDougall, 2009; Quan Luna et al., 2012). It is worth noting that channelised landslides can be classified as 'flowslides' (Hungr et al., 2001) when liquefaction occurs in the source areas; otherwise, they can be simply referred to as 'debris flows' (Hungr et al., 2001). Debris Avalanche (DA) is defined as "very rapid to extremely rapid shallow flow of partially or fully saturated debris on a steep slope, without confinement in an established channel" (Hungr et al., 2001). Avalanche formation is mostly related to bed entrainment (Cascini et al., 2013a, b; Cuomo et al., 2014). As an example of DA, the 1999 Nomash River debris avalanche (Vancouver Island, British Columbia, Canada) mobilized a volume of $3 \times 10^{5} \mathrm{~m}^{3}$ at the source, whereas the erosion processes yielded nearly the same volume, with an average erosion depth of $8 \mathrm{~m}$ measured along $25^{\circ}$ to $35^{\circ}$ steep slopes (Hungr and Evans, 2004; Hungr et al., 2005).

To overcome the numerical difficulties of modelling the soil displacements across different orders of magnitude, the failure analysis of hillslope is generally treated separately from the propagation stage with different numerical methods. While this twofold approach allows the solution of relevant technical problems, it can avoid the full understanding of the instability mechanism as a whole and, some time, can produce inaccurate results. So, a number of emerging methods have been proposed.

This paper focuses on shallow soil deposits along steep slopes, rainfall-induced instability and unsaturated coarse-grained soils. In doing that, ideal slopes, laboratory experiments (such as centrifuge tests) and real case histories will be examined. This is because evidences from laboratory and field are both fundamental. Firstly, the mechanisms of triggering, slide -flow transition and propagation will be reviewed. Then, the numerical models will be discussed.

The aim of the paper is to provide a general overview of the current potentialities for modelling such challenging phenomena. Related to that, it is chosen to subdivide the numerical results in two categories: natural and artificial slopes. While such distinction is not relevant from a mechanical viewpoint, it makes sense if one thinks that mitigation structures and design procedures need often if not always the support of numerical analyses. Most of the conceptual concepts of this paper have been previously reviewed. The same applies also to the numerical models. What is lacking in the literature is an overall discussion of both the issues in a single paper. Of course, only some types of landslides have been taken into consideration. Also a limited set of models have been used. However, the choice of the challenging category of flow-like landslides allows exploring at once the failure, post-failure and propagation stages. Correspondingly, very different mechanisms are analyzed. The novelty of this work is to combine different concepts and rielaborate previous numerical results in a more general framework. For the sake of generality, both reducedsclae experimental tests, real case histories and idealized slope schemes have been considered in the paper.

The work is organized as follows: a background about the fundamental mechanisms is firstly provided; the numerical methods are presented; then, applications are presented for both natural slopes and engineered slopes.

\section{Background \\ Triggering mechanisms}

The failure onset induced by rainfall is strictly related to the increase of pore water pressures and the consequent reduction of mean effective stresses (Anderson and Sitar, 1995; Alonso et al., 1996; Iverson et al., 1997). Within shallow soil deposits (Fig. 1), the increase of pore water pressures can be generated by rainfall that directly infiltrates the slope surface (Tsaparas et al., 2002; Futai et al., 2004) and propagate in depth through groundwater flow patterns related to the stratigraphical setting of the slope 
a

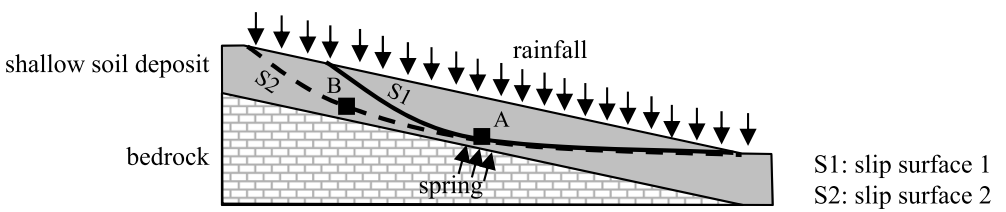

b SLIDE (dense or loose)
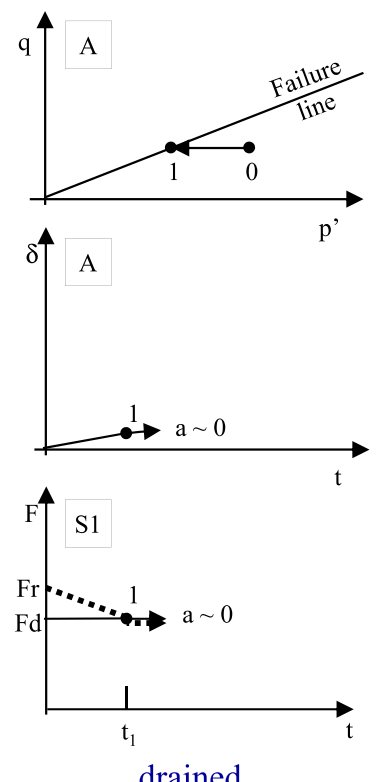

c SLIDE TO FLOW

(dense or loose)

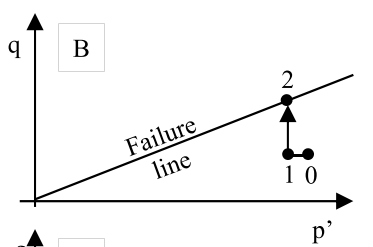

B
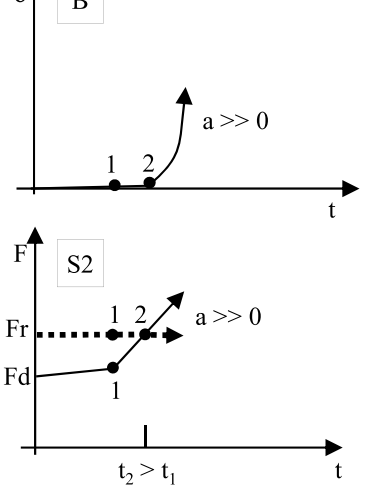

drained / undrained

\section{d FLOWSLIDE}

(loose)

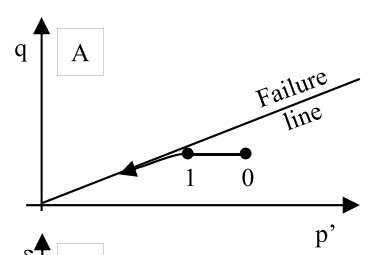

$\mathrm{A}$

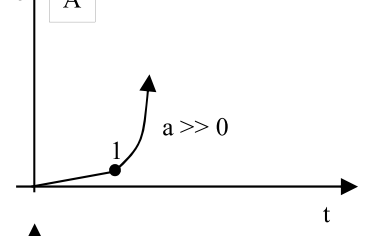

S1

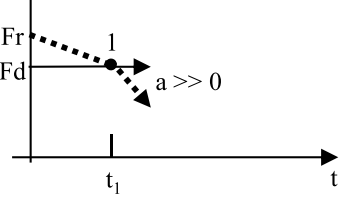

coupled

Fig. 1 Slope scheme (a) and stress paths, displacements and $F$ (Forces as $F_{r}$ : resisting forces, and $F_{d}$ : driving forces) typical of rainfall-induced (b) slide, (c) slide to flow, and (d) flowslide triggered in shallow landslides inside colluvial hollows (Cascini et al., 2010)

(Ng and Shi, 1998). Sometimes pore water pressure regime is also affected by the hydrogeological features of the underlying bedrock (Johnson and Sitar, 1990; Montgomery et al., 1997; Matsushi et al., 2006; Cascini et al., 2008) which can impose severe hydraulic boundary conditions such as water springs at the bottom of the soil deposits.

For the so-called "slides", the soil mechanical behaviour is controlled, in drained conditions, by the hydrologic response up to the failure onset. Resisting force $\left(F_{r}\right)$ gradually decreases down to the value of the driving force $\left(F_{d}\right)$ along a slip surface where the spring from the bedrock is located (later named spring zone, point $\mathrm{A}$ in Fig. 1a) (Fig. $1 b, t=t_{1}$ ). At this time lapse, the soil strength is fully mobilized. This means that the $p^{\prime}-q$ point reaches the failure line. Drained conditions are kept, both for loose and dense soils, during the postfailure stage and both displacement $(\delta)$ and acceleration (a) are low (Fig. $1 \mathrm{~b}, \mathrm{t}>\mathrm{t}_{1}$ ). In loose saturated soils, the above process is associated with a volume reduction. A so-called "flowslide" occurs (Fig. 1d, $t>t_{1}$ ), if the porewater pressure cannot freely dissipate, so that partially or totally undrained conditions develop during the post- failure stage. Particularly, in the spring zone (point A in Fig. 1), pore water pressures build up and the soil cannot sustain the imposed deviatoric stress $q$ and failed soil mass accelerates (Fig. 1d, $t>t_{1}$ ), leading to a catastrophic failure. Slides can turn into "flows" (Fig. 1c) as a consequence of complex mechanisms. First, a decrease in shear strength can occur due to local hydraulic boundary conditions such as in the spring zone $\left(t=t_{1}\right)$. Upslope (point $B$ ), the mobilised shear stresses increases, both in loose and dense soils $\left(t>t_{1}\right)$ and a further slide can occur $\left(t=t_{2}\right)$, which is characterised by a high initial acceleration. Consequently a flow is generated $\left(t>t_{2}\right)$.

Major differences between a flowslide (Fig. 1d) and a slide turning into flow (Fig. 1c) can be also outlined focusing on pore water pressures at failure. For the analysed schemes, pore water pressures reach the highest values in the spring zone (point $\mathrm{A}$ ) due to both rainfall and local hydraulic boundary conditions (i.e. spring from bedrock) and the lowest values upslope the spring zone (point B), where can be still negative at failure (Fig. 1c) and slides turning into flow can also occur in portions of the slope characterised by unsaturated conditions. 
Another important aspect to be taken into account is the type of failure. In the cases sketched in Figs. 1b-c, drained failure takes place at the critical state line, and failure can be "localized" (Pastor et al., 2002, 2004). It means that soil deviatoric strains mostly concentrate in a thin shear zone. On the contrary, fully or partially undrained post-failure stage of very loose materials (Fig. 2d) is diffuse (Darve and Lauoafa, 2000; Merodo et al., 2004). It entails that a soil volume is yielded. The difference relates mostly to pore water pressure generation, which has to be carefully considered by using suitable constitutive and mathematical models. Notwithstanding the previous differences, it can be stated that for all the landslide typologies of Fig. 1, the eventual sudden acceleration of the failed mass (post-failures stage) is a consequence rather than a cause of the slope instability process, as experimentally demonstrated by Eckersley (1990) and Chu et al. (2003). This means that the failure and post-failure stages can be separately analysed.

In the scientific literature, distinct triggering mechanisms are indicated for the inception of debris avalanches: i) the impact of failed soil masses on stable deposits, ii) direct rainfall infiltration from the ground surface, locally facilitated by anthropogenic factors such as mountain roads and tracks, iii) karst spring from bedrock as observed for pyroclastic soils in southern Italy, iv) runoff from bedrock outcrops as evidenced for shallow landslides in cohesionless soils of the Eastern Italian Alps and v) multiple failures in the landslides source areas. The scientific literature also indicate that: i) all these triggering mechanisms originate small translational slides; ii) the failed mass increases its volume inside triangular-shaped areas during the so-called "avalanche formation" which is mostly explained referring to soil liquefaction induced by impact loading; iii) soil erosion along the landslide propagation path may also play a paramount role.

Two different stages can be individuated for debris avalanches, i.e. the failure stage and the avalanche formation stage: the former includes all the triggering mechanisms which cause the soil to fail; the latter is associated to the increase of the unstable volume. Referring to these stages, four different zones can be distinguished (Fig. 2). Zone 1 corresponds to small failures which occur at natural or anthropogenic discontinuities of soil deposits, bedrock outcrops and cut slopes, respectively. Zone 2 is the impact zone of the previously mentioned failed masses that usually corresponds to water supplies from bedrock (either karst spring or water runoff at bedrock outcrops); if the Zone 1 is absent, Zone 2 is the source area of small landslides triggered by water supplies from bedrock. Zone 3 corresponds to distinct mechanisms: thrust of the failed mass upon the downslope stable material and/or soil entrainment due to the propagating mass. Zone 4 exclusively corresponds to soil entrainment. It is worth noting that while zone 1 and 2 are few tens of metres large, the width of zone 3 and 4 is not known a priori and its forecasting is a challenging task.

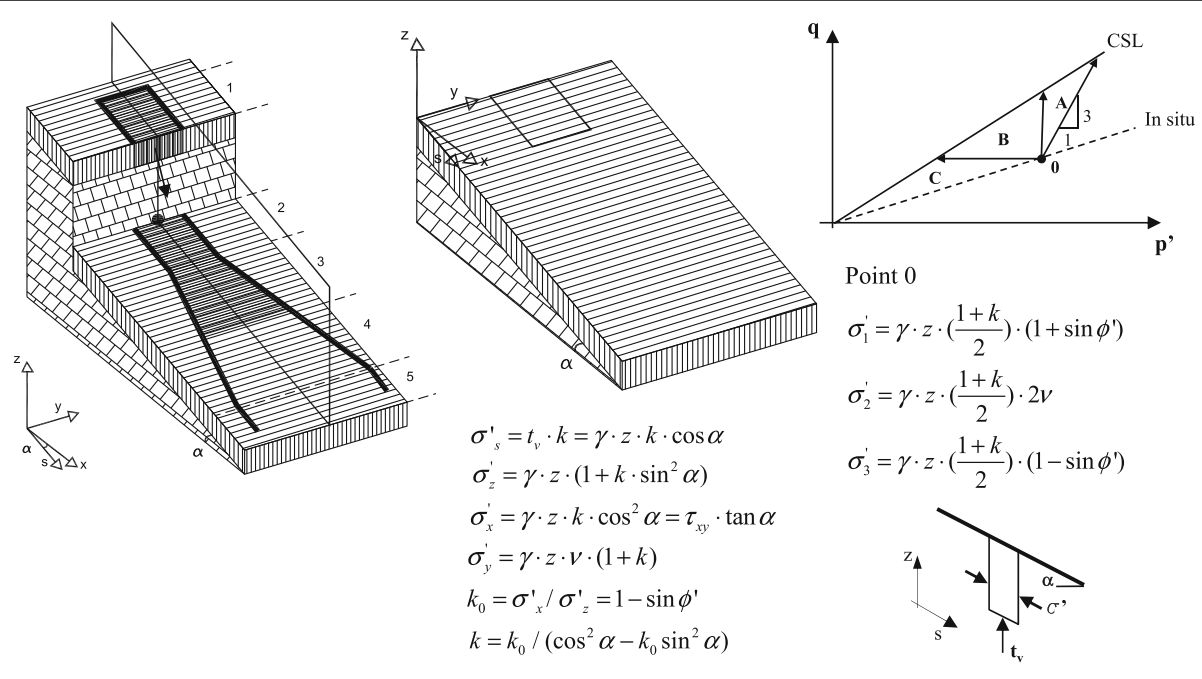

एٓa

Fig. 2 Schematic of an open slope prone to debris avalanche and stress paths relative to the triggering stage. General features: a) bedrock, b) stable soil deposit, c) failed soil, $\mathbf{d}$ ) propagating failed mass, e) entrained material, $\mathbf{f}$ ) boundary of debris avalanche, $\mathbf{g}$ ) propagation pattern. Triggering factors: I) spring from bedrock, II) impact loading. Zone 1-2: triggering. Zone 3: thrust of failed material and/or soil entrainment. Zone 4: soil entrainment. Zone 5: propagation. Stress paths for: drained impact (zone A), undrained impact (zone B), spring from bedrock (zone C), liquefaction (zone B and/or C), and thrust of failed mass on stable soils (zone B or to be determined). (Cascini et al., 2013a) 
With reference to the stages and zones in Fig. 1, the mechanics of debris avalanches can be well analysed referring to the scheme of infinite slope (Fig. 2) and to the stress invariants $q$ and $p$ '. Particularly, in-situ initial conditions (before the debris avalanche has been triggered) at the zones 2 and 3 of Fig. 1 depend on soil saturation degree $\left(S_{\mathrm{r}}\right)$ and are represented by the stress point 0 of Fig. 2. In dry condition $\left(S_{\mathrm{r}}=0\right)$ the principal stress directions $\left(\sigma_{\mathrm{i}=1,2,3}\right)$ are known (Lambe and Whitman, 1979; Iverson et al., 1997) and the normal stress values $\sigma_{\mathrm{z}}^{\prime}, \sigma_{\mathrm{y}}^{\prime}$ and $\sigma_{\mathrm{s}}^{\prime}$ can be easily obtained if the lateral earth pressure coefficient $\mathrm{k}_{0}$ refers to stress conditions at rest (Jaky, 1944). Particularly, $\sigma_{z}^{\prime}$ increases with soil depth while both $\sigma_{\mathrm{y}}^{\prime}$ and $\sigma_{\mathrm{s}}^{\prime}$ increase with slope angle. In the case of steep slopes, equilibrium conditions require high soil friction angles which correspond to low values of $\mathrm{k}_{0}$ and $\sigma_{y}^{\prime}$; consequently, the associated $\left(p^{\prime}, q\right)$ points have a high stress ratio $\eta=q / p^{\prime}$ and they lie very close to the failure criterion. For saturated soil condition $\left(S_{\mathrm{r}}=1\right)$, the soil unit weight $\left(\gamma_{\text {sat }}\right)$ and the deviatoric stress $(q)$ are higher than in the previous case while the mean effective stress ( $p^{\prime}$ ) can be either higher or lower, depending on soil unit weight $\left(\gamma_{\text {sat }}\right)$ and pore water pressure $\left(p_{\mathrm{w}}\right)$. Therefore, for saturated soil condition $\left(S_{\mathrm{r}}=1\right)$, the $\left(p^{\prime}, q\right)$ stress points can be even closer to the failure line than for dry condition $\left(S_{\mathrm{r}}=0\right)$. For unsaturated soil condition $\left(S_{\mathrm{r}}<1\right)$, the suction $(s)$ determines higher mean effective stresses ( $p$ ') than in saturated condition and a shear strength envelope with a positive apparent cohesion intercept (Fredlund et al., 1978); thus, the stress points $\left(p^{\prime}, q\right)$ are more distant from the failure criterion than in saturated soil conditions.

When an impact loading occurs (see zone 2 of Fig. 2), it mainly corresponds to an increase of deviatoric stresses; the stress paths are inside the zone A of Fig. 2 (for drained conditions) or in the zone B of Fig. 2 (for undrained conditions). In the latter case, the stress path may rapidly approach the failure criterion. However, the assumption of drained or undrained conditions can be more or less acceptable depending on loading velocity and soil conductivity and the hydro-mechanical coupling between the solid skeleton and pore fluid may play a crucial role, as discussed later. Other triggering factors such as direct rainfall infiltrating the slope ground surface, karst springs from bedrock or runoff from upslope bedrock outcrops induce stress paths in the zone $\mathrm{C}$ of the q-p' plot of Fig. 2; in these cases, fully drained conditions can be reasonably assumed (Cascini et al., 2010).

For the avalanche formation, remarks can be also outlined referring to the zone 3 of Fig. 1. Particularly, the occurrence of soil liquefaction is strongly related to the initial stress state in the q-p' plane (Fig. 2) and mechanical features of soils, thus corresponding to stress paths moving in the zone B and/or C of the q-p' plot of Fig. 2.
Analogously, the thrust of an unstable mass upon downslope stable soils cause an increase of deviatoric stresses and a stress path moving in the zone B of q-p' plot of Fig. 2. On the other hand, soil entrainment phenomena depends on the kinematic features of the propagating mass which are, in turn, related to: i) initial volume, ii) rheological behaviour and iii) hillslope topography.

\section{Mechanisms for the transformation of a slide into a flow}

Post-failure stage is a fundamental topic since it discriminates different types of phenomena. In fact, it is quite evident that the chance for a landslide to achieve high velocities depends on: i) the initial acceleration of the failed mass and ii) subsequent transformation in to a landslide of the flow type.

Anyway, the acceleration of the failed mass during the post-failure stage is associated to different mechanisms. Many Authors outline that the development of total or partial undrained conditions as the main cause of high pore-water pressures upon shearing. In particular, for loose unsaturated soils, volumetric collapse is discussed by Olivares \& Damiano (2007), Yasufuku et al. (2005), Bilotta et al. (2006) and it is observed in constant-sheardrained triaxial tests upon wetting (Anderson and Riemer, 1995; Dai et al. 1999; Chu et al. 2003; Olivares \& Damiano, 2007). For loose saturated soils, static liquefaction is introduced by Wang et al. (2002), Olivares \& Damiano (2007), Van Asch et al. (2006) and observed in undrained triaxial tests (Lade 1992; Yamamuro and Lade 1998; Chu et al. 2003) as well as in undrained ring shear tests under controlled strain rates (Wang et al. 2002). Particularly, the build-up of pore pressures is shown to be relevant for soils having low relative density index (Eckersley 1990; Iverson 2000; Wang and Sassa 2001), fine content (Wang and Sassa 2003), low hydraulic conductivity (Iverson et al. 1997; Lourenco et al. 2006) and subjected to high deformation rate (Iverson et al. 1997).

The most of the above findings are obtained through laboratory tests such as isotropically consolidated undrained triaxial tests (ICU) (Chu et al., 2003), anisotropically consolidated undrained triaxial tests (ACU) (Eckersley, 1990), constant shear-drained triaxial tests (CSD) (Chu et al., 2003) even though strain localisation is more important under plane-strain or the $3 \mathrm{D}$ conditions compared to triaxial conditions, as recently discussed by Wanatowski and Chu $(2007,2012)$. It is worth noting that all laboratory tests refer to idealized drainage conditions.

On the other hand, a direct measurement of pressures and displacements in real slopes is easy only for: i) sites monitored during the occurrence of landslides, ii) artificially induced failure in real slopes. In both cases, once the failure has occurred, the measurements cannot be repeated anymore at the same conditions. 
Further insights derive from direct observation of pore water pressures and stresses in landslides artificially induced in slope models at a reduced scale (also called flume tests). Through this approach, information can be obtained on failure and post-failure (Eckersley, 1990); however, these experiments are expensive and since they reproduce the real processes at a greatly reduced scale they may be irrespective of the full-scale slope behaviour. For instance, a large difference in stress levels may exist between model and prototype; in particular, the eventual capillary suction is out of proportion with its self-weight stress, allowing the model slope to remain steeper than would be possible at higher effective stress levels. Nevertheless, complex groundwater conditions, such as downward rainfall infiltration from ground surface and/or a downwards/upwards water spring from the bedrock to the tested soil layer, can be analysed through these tests (Lourenco et al., 2006).

A more recent approach is based on centrifuge tests which reproduce stress levels similar to those experienced by a real slope. Centrifuge tests - except for some drawbacks such as the high costs and the availability of sophisticated equipments - combine the advantages of highly instrumented slopes (such as full/reduced scale models) with the potential of geometrical configurations realistically reproducing the in-situ conditions. Particularly, Take et al. (2004) point out that the transition from slide to flow is caused by local failures producing a variation in the slope geometry. This mechanism is related to transient localized pore-water pressures that are not associated to the development of undrained conditions, but originated by the combination of particular hydraulic boundary conditions and stratigraphical settings. Experimental evidences show that the transition from slide to flow can occur both in loose and dense soils and that it can also correspond to decreasing porewater pressures during the post-failure stage. These results have been later confirmed also by other researchers through small-scale flume tests (Lourenco et al. 2006) or centrifuge tests (Lee et al., 2008, Ng, 2009; among others).

Based on previous considerations, mathematical modelling may be outlined as a powerful tool because, in principle, it can be used to investigate a wide variety of different scenarios even though the modelling of the post-failure stage is still poorly addressed in the literature such as in the case of earthquake (Pastor et al. 2004) or static perturbations (Laouafa and Darve 2002).

\section{Mechanisms of the propagation stage}

Velocities, heights and percentages of water and debris are 3D spatially distributed quantities in a landslide of the flow type (Hungr et al., 2001); they may be distributed either along the path or in a vertical direction. The propagation stage is difficult to analyse as relevant parameters such as viscosity, soil friction angle or other rheological parameters and pore water pressures cannot be easily measured in full-scale examples and direct measurements are rarely available for real cases.

These analytical difficulties exist even for channelised landslides (Hungr et al., 2001) that, independent of the triggering mechanisms occurring in the source areas (Fig. 3), propagate in ' $\mathrm{V}$ ' shaped channels with steep flanks. For instance, Fig. 3a shows a landslide source area located at the upper limit of the channel, as in the case of zero order basins (Cascini et al., 2008); alternatively, the landslide source area may be lateral to the upper limit of the channel (Fig. 3b). In either case, the propagation stage can be schematised as follows: i) at the entry of the channel, the height and velocity of the propagating mass increase and this effect is worse if two or more propagating masses join together; ii) along the channel, a great amount of material is available for bed entrainment during heavy rainstorms, and the channel may also provide water to the propagating masses, which will then fluidise, even without static liquefaction in the landslide source areas; iii) at the exit of the channel, the mass may stop or propagate further; in the latter case,

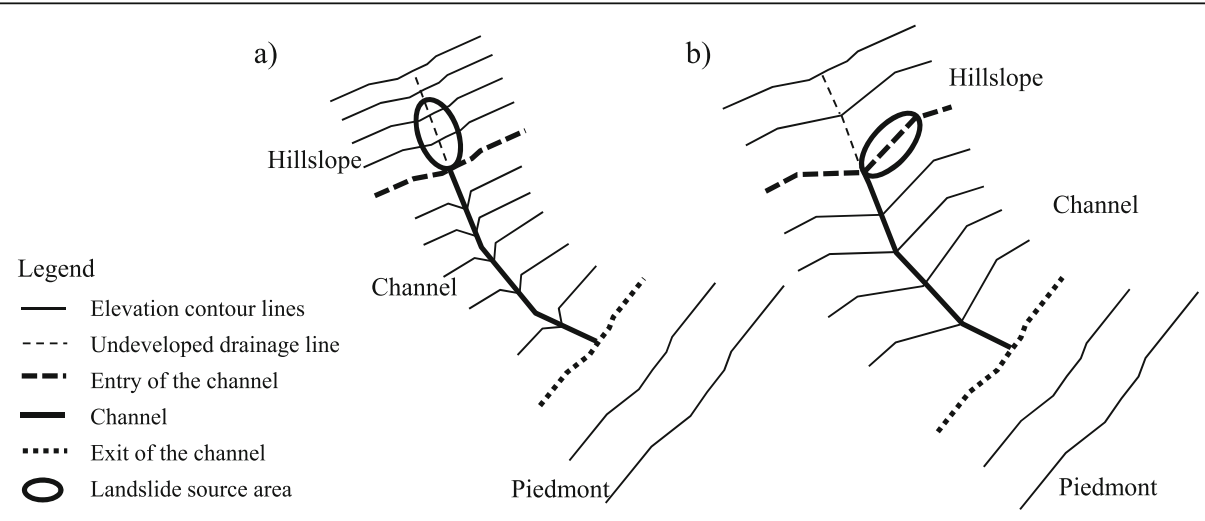

Fig. 3 Schemes of propagation patterns for channelised flows, with the source area (a) along the channel or (b) located aside 
the propagation direction is not known a priori and mass bifurcation may occur along secondary branches with different run-out distances travelled along each path; and iv) at the piedmont, deposition takes place where the channel terminates, i.e. where the longitudinal slope angle sharply decreases and cross sections are progressively wider and less deep (Fig. 3).

The prediction of propagation pattern(s), run-out distances, velocities and heights of propagating mass can reduce losses as it provides a means for i) defining the hazardous areas and estimating the intensity of the hazard and ii) working out the information for the identification and design of appropriate mitigation strategies (Fell et al., 2008).

Bed entrainment - also called erosion or basal erosion - is the process that causes an increase in the volume of flow-like landslides (Savage and Hutter, 1991; Pastor et al., 2009) owing to the inclusion of soil, debris and trees uprooted from the ground surface. In principle, the entrainment process can be simply analysed by referring to the entrainment rate $\left(e_{\mathrm{r}}\right)$, defined as the time derivative of the ground surface elevation $(z)$, over which the landslide propagates. It is generally agreed that the entrainment is positive if $z$ diminishes, i.e. $e_{\mathrm{r}}=-\delta \mathrm{z} / \delta \mathrm{t}$. However, the entrainment rate $\left(e_{\mathrm{r}}\right)$ depends on several variables: the flow structure (i.e., percentage of solid and fluid in the mixture), the density and size of the solid particles, the saturation degree of the base soil along the landslide path, the slope angle, and how close to failure the effective stresses are at the bed of the propagating mass. Bed entrainment is a crucial process increasing the landslide volume and modifying the mass velocities along the whole landslide path(s), as shown in Fig. 4. It is worth noting that landslide volume promotes the travel distance (Rickenmann, 2009), whereas bed entrainment absorbs momentum from the sliding/propagating mass and should reduce the run-out distance. However, this interplay also depends on other factors. In fact, mass velocities (and heights) determine the capability of a landslide to entrain further material and, in turn, the total entrained volume. Consequently, the percentages of water and debris change over time and so the mass rheology does. Bed entrainment also affects pore water pressures in different ways depending on slope morphology, e.g. confined/not confined flow. Therefore, bed entrainment and propagation are coupled processes that should be analysed within a unified mathematical framework. However, this interplay is not clearly addressed and modelled in the current literature.

Based on these key factors, many formulations for the entrainment rate have been proposed in the literature, and a comprehensive review of the entrainment models has been provided by Pirulli and Pastor (2012) and Cascini et al. (2014). Here, it is worth noting that most of the formulations indicate a direct proportionality between the entrainment rate $\left(e_{\mathrm{r}}\right)$ and the flow velocity $(v)$ and/or the flow depth $(h)$. Moreover, it is recognised that the occurrence of bed entrainment implies that: i) velocity and height of the flowing mass are modified, ii) pore water pressure at the base of the flow is altered, and iii) the rheology (i.e., the features and mechanical behaviour) of the flow could be modified as well if the flowing mass and the entrained materials are very different. Indeed, the entrainment process is very complex, and former contributions have been proposed based on tests (flume, centrifuge, or full scale) of differently sized, generally smaller than $10 \mathrm{~m}^{3}$, propagating volumes (Iverson et al., 2011) or numerical modelling of real debris

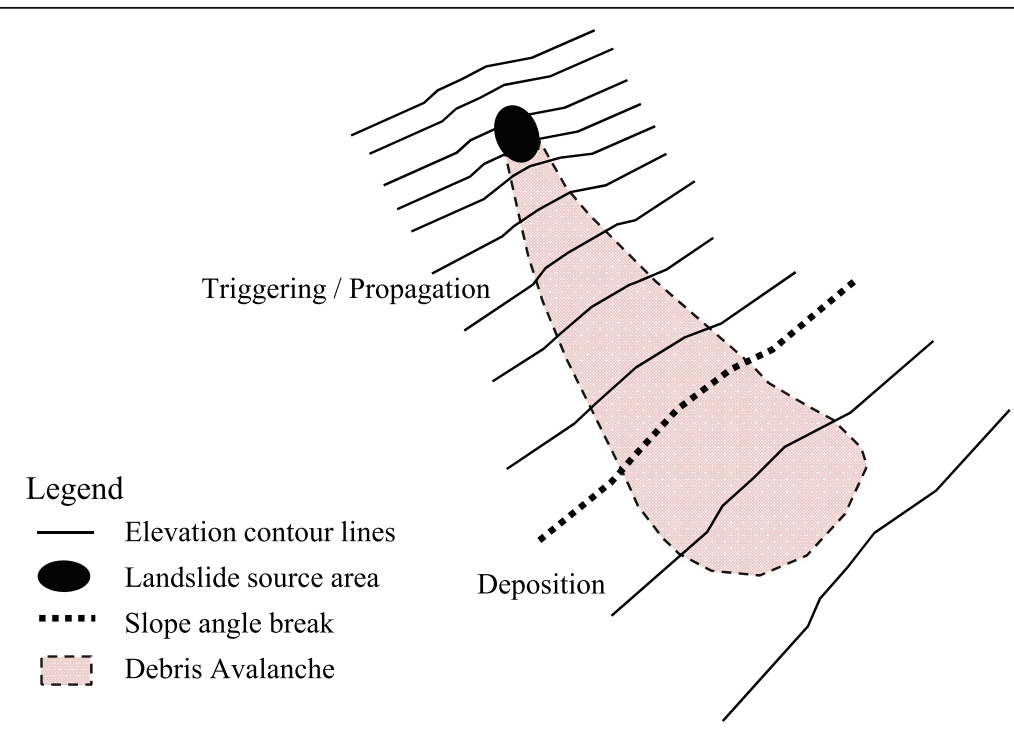

Fig. 4 Scheme for a Debris Avalanche (DA) developing as an unchannelised flow along an open slope 
flows (Cascini et al., 2014) or historical debris avalanches (Cuomo et al., 2014).

To provide further insight on the topic, this paper will focus also on real-scale landslides, particularly on debris avalanches and debris flows, and related cascading effects (Chen et al., 2006; Crosta et al., 2009; Pirulli and Pastor, 2012). Figure 5 provides a sketch for a DA evolving into a single DF (Fig. 5a); a single DA generating multiple DFs (Fig. 5b); and several DAs and DFs evolving in a single huge DF or in multiple surges delayed in time (Fig. 5c). An example of scenario "a)", the 1995 Izoard pass debris flow (southern French Alps) is characterized by an erosion thickness up to $5 \mathrm{~m}$ at the top of a $25^{\circ}$ to $30^{\circ}$ steep channel (Lake et al., 1998). An interesting debris avalanche, which bifurcated into two debris flows (scenario "b)"), occurred in Tsing Shan (Hong Kong) in 1990. Bed entrainment greatly increased the landslide volume, from 150 to $1600 \mathrm{~m}^{3}$, because of the very steep slope (approximately $40^{\circ}$ ) and the abundance of colluvial material along the slope (King 2001a, b). The scenario "c)" is typical of high mountain ridges of China and Canada (Hungr and Evans, 2004).

\section{Methods}

\section{Alternatives for landslide modelling}

Generally speaking, two main different approaches can be referred: the Lagrangian description and the Eulerian one. In the Lagrangian description, the computation points are linked to the material which is deforming and this category includes the well known
Finite Element Method (FEM) in the small displacement Lagrangian description, the Discrete Element Method (DEM) and Smoothed Particles Hydrodynamics (SPH). Among these methods, Lagrangian FEM analyses have been extensively used in solid mechanics to simulate small strains accumulated prior of failure (pre-failure stage) and at failure onset (during the failure stage) based on solid-like constitutive laws, as reviewed by Duncan (1996). Nevertheless, the FEM with Lagrangian description does not allow the description of the flow of the soil until deposition because of the tendency of the mesh to become more and more distorted. Concerning the DEM, this method is proper for modelling the behaviour of granular materials in small and large deformations: for example it is successfully applied to model granular flows with comparison against experimental laboratory evidences (Favier et al., 2009, Faug et al., 2011). However, with this method it is hard to handle large domains of space or time because of the high numerical cost necessary to compute the particle connectivity. In particular, in the field of landslides the continuity of media and kinematic fields can be often assumed and thus the benefit of DEM method is drastically reduced. Lastly, the $\mathrm{SPH}$ is developed in a continuum mechanics framework and it does not show important limitations apart from some drawbacks with boundary conditions. Up to now, this method has been mostly applied to landslide propagation problems (Pastor et al., 2009) and only recently for analyzing static equilibrium problems (Fukagawa et al., 2011).

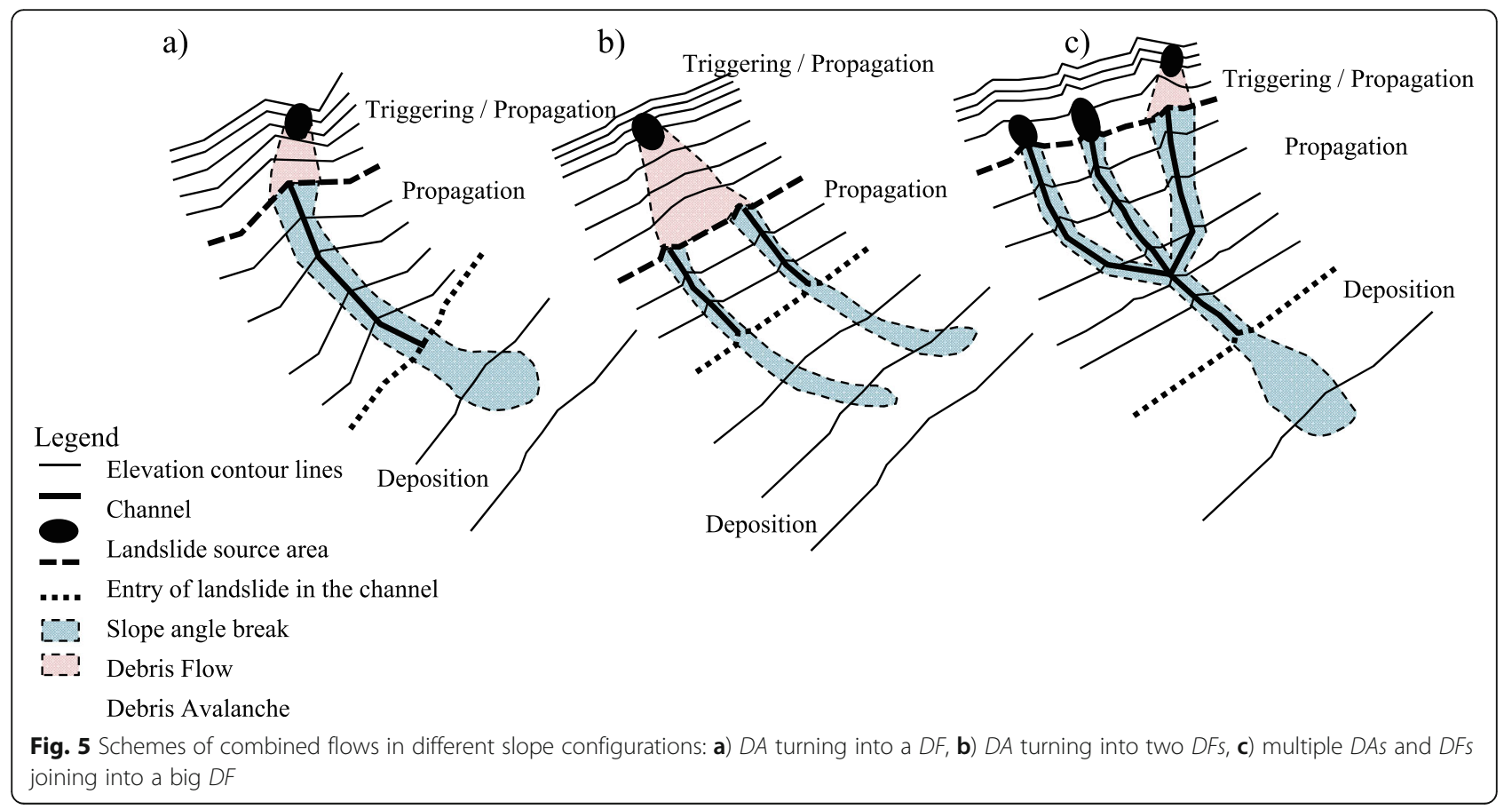


In the Eulerian description that is common in fluid mechanics, the nodes are fixed and that is why this solution is usually the best one to model a fluid-like material with large deformations in the propagation stage: there exists, for instance, the FEM with an Eulerian formulation. However, the material properties are advected across the fixed computational grid. Such a procedure causes a spurious (numerical) diffusion of history variables (e.g. plastic strains) and interfaces of heterogeneous material setting are smoothed in space through time.

Finally, some mixed methods are available which try to combine the advantages of the two main descriptions. For example, the Arbitrary Lagrangian Eulerian method (ALE) avoids the mesh tangling by allowing computation points to move but additional advection terms are required to handle transport of quantities related to the mesh and thus drawbacks of the pure Eulerian approach appear again. Still for large and complex deformation processes, such as those involved in slope stability problems, ALE cannot avoid mesh distortion and hence computation is stopped.

In fully Lagrangian FEM, SPH and DEM all the computational points coincide with material points (Fig. 6); the latter ones are not tracked in ALE and in Eulerian FEM. In order to get over the difficulties of the classical numerical methods in this framework, as an alternative the Finite Element Method with Lagrangian Integration Point (FEMLIP) (Moresi et al., 2002, 2003), is proposed as derived from the Particle In Cell method (Sulsky et al., 1995). Similar concept is that behind the Material
Point Method (MPM), which has been recently applied to a number of different slope stability and landslide cases (Wang et al., 2016, 2018; Ghasemi et al., 2018, 2019; Cuomo et al., 2019a, b). Both methods and others similar available in the literature are based on a kinematic dissociation between the material points and the computational nodes of the finite element Eulerian mesh. For a given material configuration, the material points are used as integration points on one element. The resolution of the equilibrium equation at the nodes gives a velocity field. At the end of each step, the velocity is interpolated from the nodes to the material points which are moved accordingly throughout the fixed mesh up to a new configuration. Since all material properties including internal variables are stored at material points, they are accurately tracked during the advection process. Actually, thanks to this dissociation between mesh nodes and material points, such approach benefits both from the ability of an Eulerian FEM (the mesh is kept fixed) to support large transformations, and from the possibility of a Lagrangian FEM to track internal variables during the material movement. This method is - in principle - suitable to deal with: i) static equilibrium of elasto-plastic materials in the pre-failure stage, ii) large deformations upon failure, iii) large displacements during the propagation stage while still tracking the history of material properties.

\section{Models for landslide triggering simulation}

Several approaches are currently available for the slope analysis and they allow separately modelling the failure,

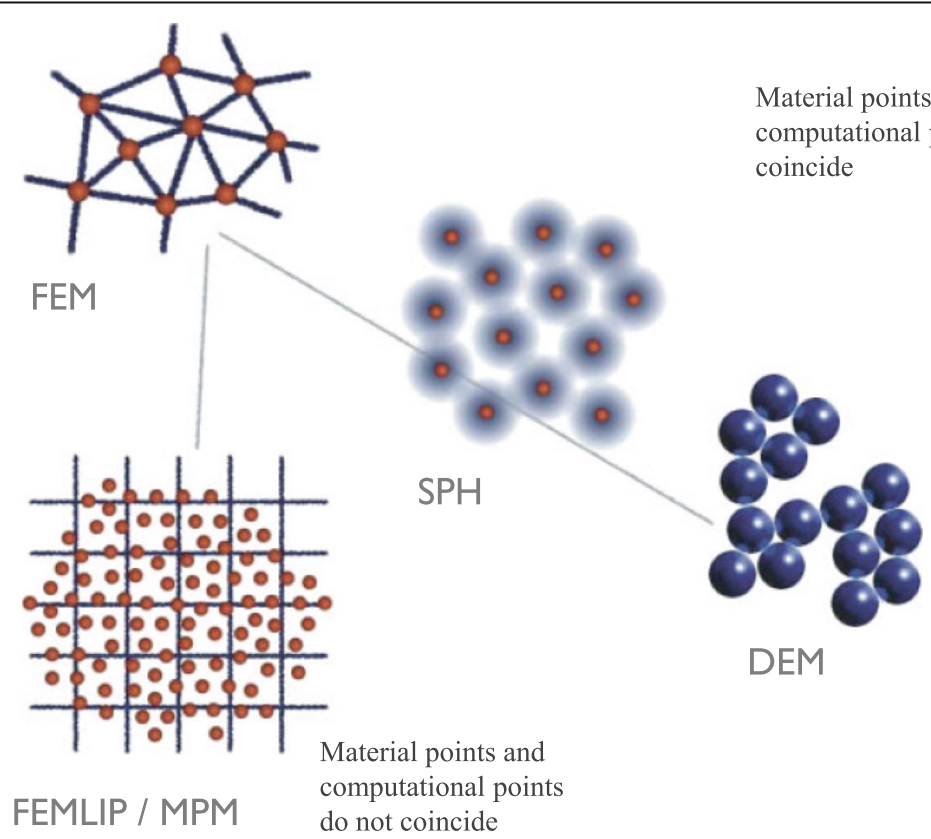

Fig. $\mathbf{6}$ Scheme of different methods for the analysis of soil deformation and slope failure 
post-failure and propagation stages of hillslope instability phenomena. They are divided in three broad classes depending on the amount of deformation taken into account.

Particularly, the failure stage can be analysed using many standard engineering methods that, anyway, disregard the deformations prior to failure and during the failure stage; these methods are usually called Limit Equilibrium Methods (LEM, later on) which include the Infinite Slope Method (ISM, hereafter) and the so-called slice methods proposed under distinct hypotheses by many Authors (Morgenstern \& Price, 1965; Janbu, 1954; among others). In these methods the constitutive law of the material is rigid-perfectly plastic and thus the displacements along the slip surface cannot be assessed.

The result of LEM analysis is the so-called factors of safety (FS), which has been extensively used to satisfactorily tackle a number or real cases in the last decades. Particularly, both failures and stable conditions computed via LEM have been fully confirmed by in-situ evidences of natural or man-made slopes (Leroueil, 2004, among others).

More sophisticated approaches are available which allow computing soil deformations and displacements in boundary value problems. In order to properly reproduce the previously described typologies of shallow landslides, it is necessary to use a (i) mathematical model describing the coupling between pore fluids and soil skeleton, (ii) a suitable constitutive relationship able to describe the unsaturated soil behaviour, and (iii) a numerical model where (i) and (ii) are implemented. To the authors' knowledge, these have not been done yet in a full satisfactory manner, and until such tools are available, simplified models have to be carefully used.

This paper uses the mathematical framework derived from the fundamental contributions of Zienkiewicz et al. $(1980,1999)$. This framework can be profitably used to simulate the landslide failure and post-failure stages. It is assumed that the soil consists of a solid skeleton and two fluid phases, water and air, which fills the voids. The movement of the fluid is considered as composed of two parts, the movement of soil skeleton and motion of the pore water relative to it. The total stress tensor acting on the mixture is decomposed into a hydrostatic pore pressure term and an effective stress tensor acting on soil skeleton, which can be also extended to the case of unsaturated soils. In the balance of momentum equation for the mixture the acceleration of water relative to soil grains is neglected. Whereas, the deformation of soil skeleton, the deformation of soil grains caused by pore pressure, the deformation of pore water caused by pore pressure, and the increase of water storage are considered. The Darcy law is used to describe water flow through the soil skeleton, although other alternatives can be chosen. In above, the acceleration terms of the pore water relative to soil skeleton are neglected, and the space derivatives of accelerations are assumed to be small. Finally, the model is completed with kinematic relations linking velocities to rate of deformation tensor and a suitable constitutive equation. More details are provided by Pastor et al. (2004). In the next sections the "GeHoMadrid" code will be used combined to either standard constitutive models like Drucker Prager (DP) or advanced constitutive models like that proposed by Pastor and Zienkiewicz (1990), (PZ).

\section{Models for the simulation of landslide propagation}

Several methods have been developed to analyse the landslide propagation.

Empirical methods are based on field observations and identify relationships between landslide volume, local morphology, presence of obstructions and landslide runout distance. The availability of landslide datasets has encouraged statistical (bivariate and multivariate) analyses that point out indexes directly (or indirectly) related to landslide mobility. To date, these empirical models have provided an estimation of run-out distance that can be correlated to i) the amount of the unstable volume (Corominas, 1996) and ii) the features of landslide source areas (e.g. width/length ratio, depth of slip surface) or slope morphology (Cascini et al., 2011b). These approaches are commonly used for the backanalysis of case histories; they capture the global observed behaviour (high mobility) of these landslides, but disregard crucial local effects (e.g. diversions and/or bifurcations).

Analytical methods simulate the landslide propagation using physical-based equations derived from solid and fluid dynamics (Pastor et al., 2009; Pirulli and Sorbino, 2008; Hungr and Mc Dougall, 2009). Thus, velocity and height are provided alternatively at (i) each point of a given domain in Eulerian-formulated models or (ii) at each point of the propagating mass for Lagrangian approaches. The three main categories of the Lagrangian approaches are i) block ('lumped mass') models, ii) twodimensional models that look at a typical section profile of the slope, neglecting the width dimension, and iii) threedimensional models treating the flow of a landslide over an irregular 3D terrain. Most of the models belonging to the latter two categories are simplified by integrating the internal stresses in either the vertical or bed-normal direction to obtain a form of St. Venant equation. Then, the governing equations are solved using numerical methods such as finite difference (O’Brien et al., 1993), finite element (Pastor et al., 2002), finite volume (Pirulli and Sorbino, 2009; Pirulli and Pastor, 2012) or smooth particle hydrodynamic (SPH) (Pastor et al., 2009). Among the governing equations, the rheological model poses important 
scientific and practical difficulties; rheological parameters can often only be obtained from the back-analysis of case histories, and thus simple models are preferred because a limited number of parameters can be constrained more easily. It is worth noting that only a few models schematise the propagating mass as a mixture of solid grains and pores, thus providing information on pore water pressures in space and time (Pastor et al., 2011).

Different hypotheses have been formulated for the entrainment onset: i) velocity threshold, ii) dependency on slope angle (Brufau et al., 2000, Egashira et al., 2000, 2001; Papa et al., 2004); and iii) correlation with landslide volume (Chen et al., 2006). Alternatively, the socalled 'erosion rate' $\left(e_{\mathrm{r}}\right)$ may be invoked, which is defined as the time derivative of the ground surface elevation and is equal to the time derivative of the soil depth of the propagating mass when other causes are not in play. The erosion rate can be modelled as proportional to the product of velocity $(v)$ and propagation height $(h)$. In this case, it is convenient to refer to the landslide grow rate' $\left(E_{\mathrm{r}}\right)$, which is independent of the flow velocity. Once assigned an $E_{\mathrm{r}}$, the amount of bed entrainment depends on both the height and velocity of the propagating mass at each point of the landslide path. The terms $e_{\mathrm{r}}$ and $E_{\mathrm{r}}$ are related by the equation $e_{\mathrm{r}}=E_{\mathrm{r}} \cdot h \cdot v$. Takahashi et al. (1991) relate $E_{\mathrm{r}}$ to two factors: the solid concentration of the propagating mass and the availability of solid particles along the landslide path. However, Hungr (1995) relates $E_{\mathrm{r}}$ to the initial and final landslide volume and to the travelled distance $(L)$ in the following way: $E_{\mathrm{r}^{*}}=\ln \left(V_{\text {final }} / V_{\text {initial }}\right) / L$, where $V_{\text {initial }}$ is the volume entering an erodible zone of the slope, and $V_{\text {final }}$ is the sum of the initial volume and the entrained material. In more complex formulations the growth rate depends on the solid concentration, slope angle and shear strength of the eroded material (Ghilardi et al., 2001).

Analytical approaches to bed entrainment analysis require a proper rheological (or constitutive) model for the behaviour of the interface between the propagating landslide and the ground surface. Bed entrainment is also related to flow structure, density, size of particles and how close to failure the effective stresses at the ground surface are. To the authors' knowledge, there are very few analytical models for bed entrainment in the current literature. Medina et al. (2008) relate $e_{\mathrm{r}}$ to factors such as i) landslide velocity, ii) shear stress mobilised at the base of the propagating mass, iii) slope angle, and iv) unit weight of the propagating material. Quan Luna et al. (2012) proposed a 1D analytical model for erosion assessment based on limit equilibrium considerations and the generation of excess pore water pressure through undrained loading of the in-situ bed material; similar approaches could provide fully realistic results if extended to 3D conditions. Analytical approaches have rarely been implemented in numerical codes and thus their application to real case histories is still limited.

Finally, mixed methods combine analytical methods for propagation and empirical methods for bed entrainment. Mixed methods have been recently applied by Hungr and McDougall (2009) and Pastor et al. (2009) to landslides of the flow type. All of these contributions refer to the empirical erosion law of Hungr (1995) and it is worth comparing their back-analysed values of $E_{\mathrm{r}}$, which span a wide range of values due to differences in site conditions and soil properties. However, the estimated entrainment coefficients in these analyses also depend on both the chosen rheological model and the calibration procedure for the rheological parameters. Therefore, further applications of numerical approaches to real case histories are necessary to better assess the potential bed entrainment during the landslide propagation stage. Therefore, in this study a relevant case history from Southern Italy is analysed.

The 'GeoFlow_SPH' model proposed by Pastor et al. (2009) is applied here below. The model is based on the theoretical framework of Hutchinson (1986) and Pastor et al. (2002) and schematises the propagating mass as a mixture of a solid skeleton saturated by water; the unknowns are the velocity of the solid skeleton $(v)$ and the pore water pressure $\left(p_{\mathrm{w}}\right)$.

The governing equations are i) the balance of the mass of the mixture combined with the balance of the linear momentum of the pore fluid, ii) the balance of the linear momentum of the mixture, iii) the rheological equation relating the soil stress tensor to the deformation rate tensor, and iv) the kinematical relations between the deformation rate tensor and the velocity field. From this, we derive a propagation-consolidation model by assuming that pore water pressure dissipation takes place along the normal to ground surface, and the velocity of the solid skeleton and pressure fields can be split into the sum of two components related to two processes: propagation and consolidation (for further details see Pastor et al, 2009). The initial pore water pressure is taken into account through the relative height of the water, $\mathrm{h}_{\mathrm{w}}{ }^{\text {rel }}$, which is the ratio of the height of the water table to the soil thickness, and the relative pressure of the water $\mathrm{p}_{\mathrm{w}}{ }^{\text {rel }}$, that is to say the ratio of pore-water pressure to liquefaction pressure. Estimates of both parameters can be obtained from the analysis of the triggering stage, and they play an important role in the propagation stage of a flow-like landslide (Cuomo et al., 2014b). In the model here used, the vertical distribution of pore water pressure is approximated using a quarter cosinus shape function, with a zero value at the surface and zero gradient at the basal surface (Pastor et al., 2009), and the timeevolution of the basal pore water pressure $\left(p^{\mathrm{b}}{ }_{\mathrm{w}}\right)$ relates to the consolidation factor $\left(\mathrm{c}_{\mathrm{v}}\right)$. 
As many flow-like landslides have small average depths in comparison to their lengths or widths, the above equations can be integrated along the vertical axis and the resulting 2D depth-integrated model presents an excellent balance of accuracy and simplicity. The GeoFlow_SPH model also accounts for bed entrainment along the landslide path, and the elevation of the ground surface consistently decreases over time. In addition, different empirical erosion laws can be implemented in the GeoFlow_SPH model (e.g. Hungr, 1995; Blanc, 2011; Egashira et al. 2000, 2001; Blanc et al., 2011; Blanc and Pastor, 2011, 2012a and 2012b). The simple yet effective law proposed by Hungr (1995) is used mainly to achieve results comparable to those available in the literature. Hungr (1995) relates $E_{\mathrm{r}}$ to the initial and final landslide volume and to $L$; the entrained material is assumed to have nil velocity and nil pore water pressure when entrained by the propagating mass.

In the GeoFlow_SPH model, the Smoothed Particle Hydrodynamics (SPH) method is used; this method discretises the propagating mass through a set of moving 'particles' or 'nodes'. Information, i.e. unknowns and their derivatives, is linked to the particles, and the SPH discretisation consists of a set of ordinary differential equations whose details are provided by Pastor et al. (2009). The accuracy of the numerical solution and the level of approximation for engineering purposes depend on how the nodes are spaced and how the digital terrain model (DTM) is detailed, as recently reviewed by Pastor and Crosta (2012) and Cuomo et al. (2013).

\section{Results and discussion for natural slopes}

\section{Failure of shallow soil covers}

A first example of landslide triggering simulation is provided for three different combinations of shallow covers potentially unstable due to rainfall from ground surface combined to water spring from the bedrock. This is a recurrent site condition in several geoenvironmental contexts.

Three infinite slope schemes are referred and parametric analyses are performed with typical slope angles (35 degrees), depths $(4.5 \mathrm{~m})$ and stratigraphical settings (Fig. 7) provided by the in-situ evidences (Cascini, 2004). Particularly, the three schemes well averages the stratigraphy of pyroclastic covers located around the Vesuvius volcano (Naples, Italy), like the Pizzo d'Alvano massif,
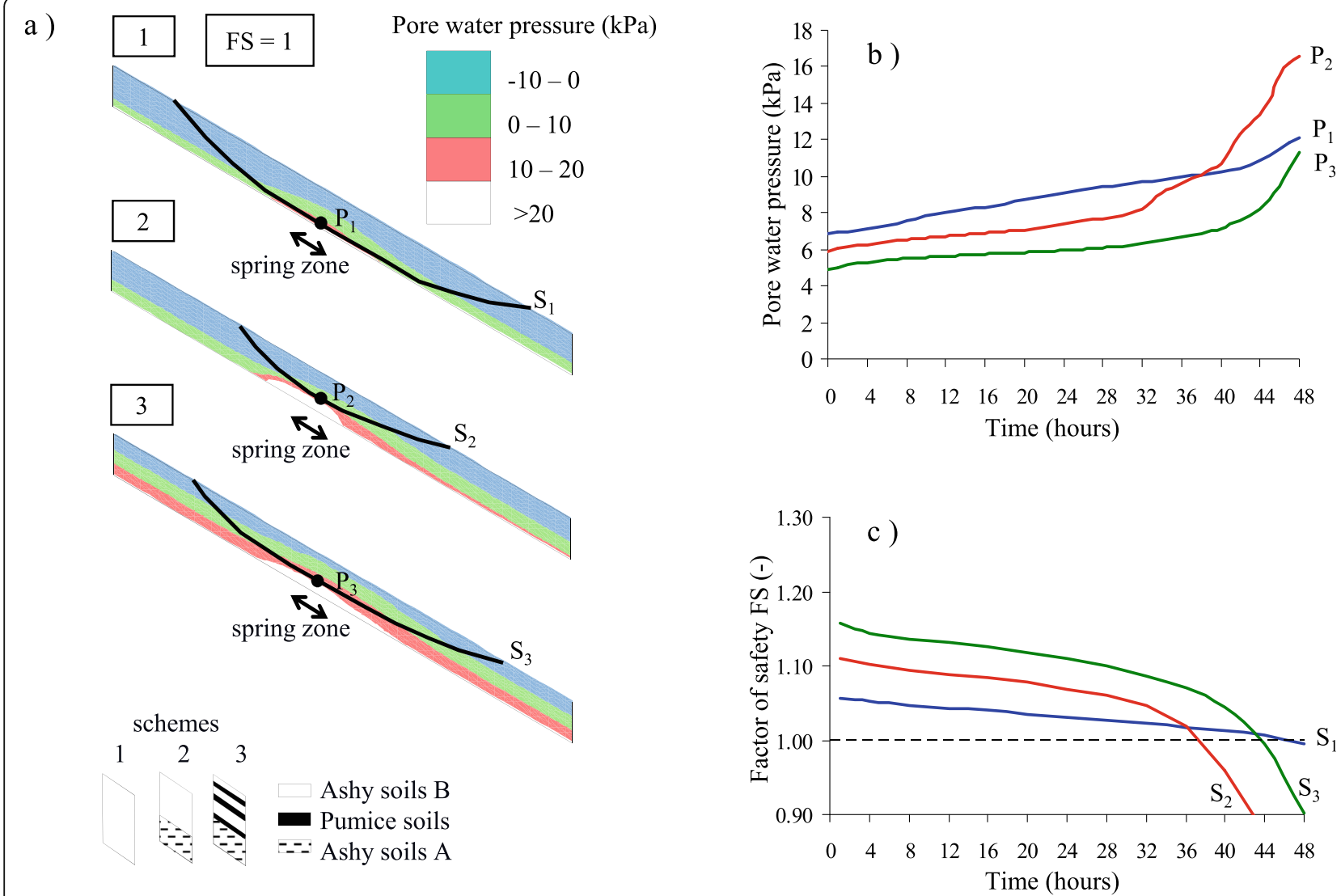

Fig. 7 Results of numerical modelling for seepage and slope stability analysis. a) Pore water pressure computed at failure (FS: Factor of Safety equal to 1) for different slope schemes (1-3), b) pore water pressure versus time at a representative point along the slip surface for each slope, $\mathbf{c}$ ) Factor of Safety versus time for the slip surfaces (S1-S3) (Cascini et al., 2010) 
where impressive flow-like landslides occurred in 1998. The geomechanical modelling of the pore water pressure is performed for the time period from January 1, 1998 to May 5,1998 , by using the commercial finite element code SEEP/W (Geoslope, 2005). The main soil parameters are here summarised: i) Ashy soil A (porosity, $n$ : 0.66; saturated unit weight, $\gamma_{\text {sat }}: 15.7 \mathrm{kN} / \mathrm{m}^{3}$; saturated conductivity, $k_{\text {sat }}: 10^{-6} \mathrm{~m} / \mathrm{s}$; friction angle, $\phi^{\prime}: 35^{\circ}$; effective cohesion, $\left.c^{\prime}: 10 \mathrm{kPa}\right)$; ii) Ashy soil B ( $n: 0.58 ; \gamma_{\text {sat }}: 13.1$ $\left.\mathrm{kN} / \mathrm{m}^{3} ; k_{\mathrm{sat}}: 10^{-5} \mathrm{~m} / \mathrm{s} ; \phi^{\prime}: 37^{\circ} ; \mathrm{c}^{\prime}: 0 \mathrm{kPa}\right)$; iii) Pumice soils (n: $0.69 ; \gamma_{\text {sat }}: 13.1 \mathrm{kN} / \mathrm{m}^{3} ; k_{\text {sat }}: 10^{-4} \mathrm{~m} / \mathrm{s} ; \phi^{\prime}: 37^{\circ}$; c': 0 $\mathrm{kPa})$. More details on the characterization of pyroclastic soils can be found in Cascini et al. (2010).

The adopted FEM mesh consists in 3755 quadrilateral elements with lengths and heights respectively smaller than $1.0 \mathrm{~m}$ and $0.5 \mathrm{~m}$. As initial conditions, suction values are assumed respectively equal to $5 \mathrm{kPa}$, all over the slope section. Daily rainfall intensity is applied as flux boundary condition at the ground surface for the period January 1, 1998 - May 3, 1998; hourly rainfall intensities are assigned for the last 2 days (May 4-5). At the contact between the pyroclastic deposit and the limestone bedrock, an impervious condition is assumed except for the zone where the spring from the bedrock is located (Fig. 7). Here, a flux condition is considered with a flux value of $1.67 \times 10^{-5} \mathrm{~m}^{3} / \mathrm{s}$, starting from 2 nd or 3th May 1998. Using the computed pore pressures values, slope stability conditions are evaluated. To this aim, the limit equilibrium methods proposed by Janbu (1954) and Morgenstern and Price (1965) are adopted and the corresponding factor of safety values are computed by using the commercial SLOPE/W code (Geoslope, 2005). For all the involved soils, a rigid-perfectly plastic constitutive model is referred considering, in both saturated and unsaturated conditions, the extended Mohr-Coulomb failure criterion proposed by Fredlund et al. (1978) with geotechnical properties listed in Table 1. The numerical results of the parametric analysis (Fig. 7) indicate that rainfall infiltration from ground surface and spring from the bedrock increase the pore water pressures up to the slide occurrence (Fig. 2b), independently from the assumed stratigraphical setting and for any shear strength value listed in Tab. 1. Different stratigraphical settings and mechanical properties of pyroclastic deposits anyhow determine different depths of the slip surfaces from the ground surface (Cascini et al., 2005).

The successful application of the uncoupled approach based on the use of unsaturated transient seepage analysis and limit equilibrium slope stability analysis is worth of twofold comments. On one hand, this approach is relative simple to apply and based on the use of codes easily available for researchers and practitioners. On the other hand, the main physical processes and the key factors are properly taken into account so that a satisfactory interpretation of complex slope stability problems is obtained.

The main limitation of such type of application is that no information can be derived about the post-failure events. Will the soil liquefy or not? There will be any transformation into a flow? No answer will be obtained to these relevant questions, unless other approaches are used.

\section{Transformation of a slide into a flow}

The observation of soil liquefaction, slope fluidization, and similar phenomena is seldom observed or quantitatively measured in the field. For this reason, it is very useful to refer to laboratory slope experiments. Until few years ago, the option of small-scaled slopes is the only chance to consider. More recently, centrifuge tests allowed having almost a 1:1 correspondence between the prototype and real boundary value problems. The centrifuge tests of Take et al. (2004) are here analysed using the GeHoMadrid code. In the numerical analyses an unstructured mesh is used with triangular elements on average not larger than $0.4 \mathrm{~m}$. A null pore water pressure values is assumed at point $\mathrm{E}$ - corresponding to the water table level observed at failure during the tests - to reproduce the raising of the water table in the upper soil layer. In the FEM analysis, pore water pressure is allowed to change in space and time, starting from an initial value of $-5 \mathrm{kPa}$ throughout the slope model. This is adequately taken into account referring to Bishop's stresses (for details see Pastor et al., 2002). However, for sake of simplicity, numerical analyses are performed in the hypothesis of fully saturated conditions and the used version of the $\mathrm{PZ}$ constitutive model fits this hypothesis (Pastor et al., 1990; Merodo et al., 2004). Of course, the analyses could be extended to the case of unsaturated conditions but this is beyond the scope of the present paper. The soil mechanical properties are either taken from GEO (1999), $\mathrm{Ng}$ et al. (2004) and Take et al. (2004), e.g. $\gamma_{\mathrm{sat}}=14 \mathrm{kN} / \mathrm{m}^{3}, \mathrm{e}=0.32$ (Dense soil) or 0.62 (Loose soil), $\mathrm{M}_{\mathrm{g}}$ and $\mathrm{M}_{\mathrm{f}}$, or indirectly estimated/calibrated, e.g. $k_{\text {sat }}=10^{-4} \mathrm{~m} / \mathrm{s}, \mathrm{E}, \eta, \mathrm{H}_{0}$, comparing the experimental evidences and the numerical results. It is worth noting that two different values of $\mathrm{M}_{\mathrm{f}}=0.825$ (Dense soil) or 0.550 (Loose soil) are assumed which derive from different values of relative soil density while the same critical friction angle $\left(\mathrm{M}_{\mathrm{g}}=1.375\right)$ and bulk modulus $\left(\mathrm{K}_{\mathrm{ev} 0}=11.5 \mathrm{e}^{3} \mathrm{kPa}\right)$ are considered for both loose and dense soils. This strong assumption is aimed at emphasizing in a limit case the role played by soil porosity as a fundamental factor for slope behaviour upon failure and beyond. The details of such soil characterization are given in Cascini et al. (2013b), and also more insights about the calibration of the constitutive model parameters are given in Cuomo et al. (2018). 
Hydro-mechanical coupled quasi-static analyses are performed to take into account the coupling between the solid skeleton and pore fluid. The simulated plastic strains significantly differ in the case of loose and dense soil (Fig. 8) for both the value (larger for loose soil) and extent of the affected zone. In the case of loose soil, "diffuse" plastic strains are simulated, firstly at the toe of the slope, and then they involve a larger amount of the slope as time elapses. For dense soil, plastic strains appear firstly at the toe of the slope and then they are "localized" along a slip surface where plastic strains accumulate as the process evolves. The above mentioned differences depend only on relative density being the other mechanical properties equal in the two cases. However, apart from the different type of failure, i.e. diffuse or localized, a different time evolution is also outlined. For loose soil, the failure stage is shorter because higher excess pore water pressures rapidly accumulate in the slope until it fails. Conversely, in the case of dense soil, both the pre-failure stage (mainly corresponding to elastic strains) and the failure stage are longer in time.

In this case, the use of a sophisticated hydromechanical approach combined to an advanced constitutive model is mandatory to reproduce the transformation of a slide into a flow. The use of such approach can highlight how a contractive loose soil slope undergoes a significant build up of pore water pressure due to a rainfall-induced soil volume change (Cascini et al., 2013b). Based on limit equilibrium analysis, the slope would be stable while using a more adequate approach, such that used here, the slope will fail. More details on such scenarios are given in Cascini et al. (2013b).
The main limitation of the approach showed here is that the equations are all written in the framework of "small deformations", which means that once the deformed slope configuration becomes too much distorted compared to the original slope, the simulation stops or the numerical results are unreliable.

\section{Modelling the propagation stage of debris flows (DFs)}

The SPH model is here applied to a real case of two debris flows converging inside the same valley channel. A $3 \times 3 \mathrm{~m}$ DTM is used as input for the GeoFlow_SPH model, as it accurately reproduces the topographical/ morphological conditions of the sites before the event and the anthropogenic streets/channels (5-10 m large). The extent of the landslide source areas and the initial depths of the propagating masses are obtained from detailed landslide inventory maps and soil thickness maps at the 1:5000 scale (Cascini et al., 2005; Cuomo, 2006). Specifically, the landslide source areas have lengths of $250-400 \mathrm{~m}$ and widths of $50-200 \mathrm{~m}$, and initial soil thicknesses in the range of 3-4.5 m. At point ' 1 ' of Fig. 10, the eroded depths are $1-2 \mathrm{~m}$ and the piedmont areas, shown in red, indicate the piedmont areas hit by the flowslides. To set up the numerical simulations, 2936 and 4598 points are considered within the two landslide source areas of Sarno. In each zone, the points are spaced at $3 \mathrm{~m}$ at the beginning of the computation. Furthermore, the two propagating masses are released at once from the source areas, thus disregarding the possibility of multiple/delayed failures. The frictional rheological law is used, with the rheological properties $\left(\tan \phi_{\mathrm{b}}=0.4\right)$ selected first by referring to Pastor et al.

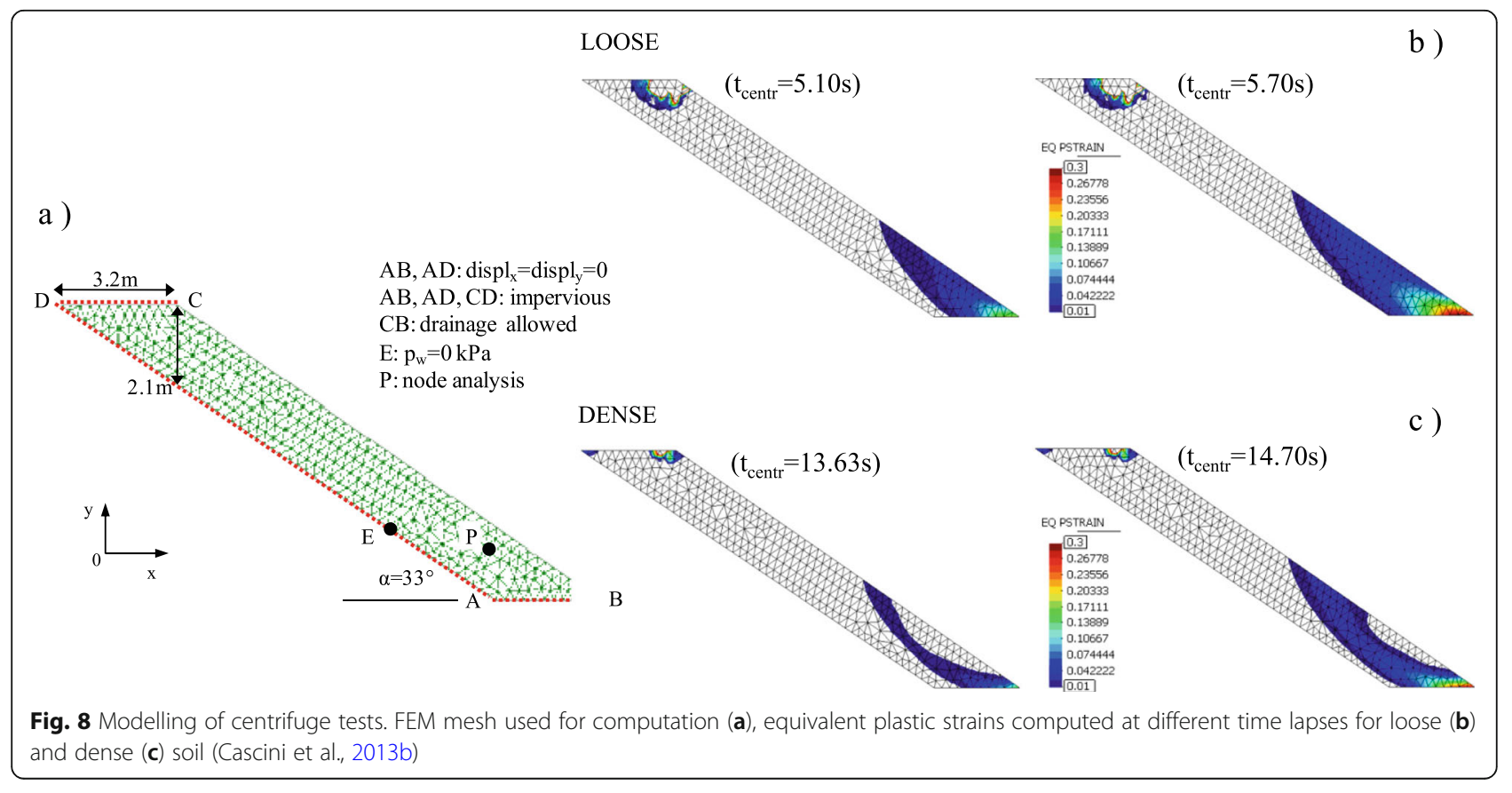


(2009) and then with different hypotheses considered for the erodible areas $\left(A_{\mathrm{er}}\right)$, and $E_{\mathrm{r}}$. In particular, the propagation path is divided into three zones: hillslope, channel and piedmont. The numerical simulations consider erosion in channel and piedmont zones, or only in the channel zone. Moreover, different $E_{\mathrm{r}}$ values, ranging from $9 \times 10^{-4}$ to $1.3 \times 10^{-3} \mathrm{~m}^{-1}$, are used to backanalyse the case studies. The initial pore water pressure normalised to soil liquefaction pressure $\left(p_{\mathrm{w}}{ }^{\text {rel }}=p_{\mathrm{w}} /\right.$ $\left.\gamma_{\mathrm{sat}} \cdot h\right)$, where $p_{\mathrm{w}}{ }^{\text {rel }}$ is the so-called 'normalised pore water pressure' and $\gamma_{\text {sat }}$ is the soil unit weight) is assumed equal to 1.0 inside the landslide source area. An automatic adaptive time stepping is used for time discretisation (Pastor et al., 2002) with time steps shorter than $0.8 \mathrm{~s}$. The Runge-Kutta algorithm is used for numerical time integration, as suggested by Pastor et al. (2009).

The results show that the bed entrainment greatly modifies the landslide propagation pattern (Fig. 9). In case 1 , only the channel is erodible and the simulated landslide travels mainly at the right-hand side. In case 2, the propagating mass entrains material along the whole propagation path and the simulated bed entrainment causes the material deposition and reduces the landslide run-out distance. In both cases, SPH modelling provides distinct propagation areas, similar run-out distances and run-outs shorter than the observed one of about $400 \mathrm{~m}$. Assuming the highest $E_{\mathrm{r}}$ value (case 3), the field evidence is poorly reproduced, as in the model the landslide stops at the exit of the channel where a thick deposit is simulated and the propagation path observed at the piedmont in the case study is not captured. However, the results show that bed entrainment slightly modifies the duration of the whole propagation/deposition stage (45 to $50 \mathrm{~s}$ for cases 1-3). Moreover, the comparison with the case 4 highlights the important role played by the initial height of the water table $\left(h_{\mathrm{w}}{ }^{\mathrm{rel}}=0.4\right.$ instead of 0.25 ).

The numerical results satisfactorily reproduce the insitu evidence for both the run-out distance and the extent of the propagation-deposition zones. The simulated phenomenon lasted about $60 \mathrm{~s}$, which is in agreement with Pastor et al. (2009) and eyewitness accounts of inhabitants (Cascini et al., 2005).

\section{Modelling the propagation stage of debris avalanches (DAs)}

Lateral spreading combined to the bed entrainment is another fundamental mechanism governing the propagation stage. To assess the roles of entrainment, frictional basal resistance and pore water pressure in the lateral spreading of the propagating mass, an ideal slope is parametrically analysed. The slope consists of two planes dipping at $i_{1}$ and $i_{2}$ (Fig. 10). The failed volume is located at the uppermost edge of the upper slope, inside the source area. The propagation area of a debris avalanche is analysed with reference to the semi-apical angle $(\beta)$ computed from the lateral boundary of the debris avalanche to its axis at the source area. Other important features, such as the angle of reach $(\alpha)$ formed by the line connecting the uppermost point of the landslide crown scarp to the tip of the mass deposit in a longitudinal section, are not investigated here, as they also depend on piedmont characteristics (Cascini et al., 2011b).

Several analyses of frictional-like materials are performed by varying the morphometric features of the hillslope $\left(i_{1}, i_{2}, H_{\text {slope }}\right)$, the geometrical aspect ratio of the source area $\left(B_{\text {trig }}, L_{\text {trig }}, h_{\text {trig }}\right)$ and the main rheological parameter (the friction angle of the propagating mass, $\left.\phi_{\mathrm{b}}\right)$. A fixed value for landslide growth rate $\left(E_{\mathrm{r}}\right)$ is used to account for the entrainment phenomena. The results

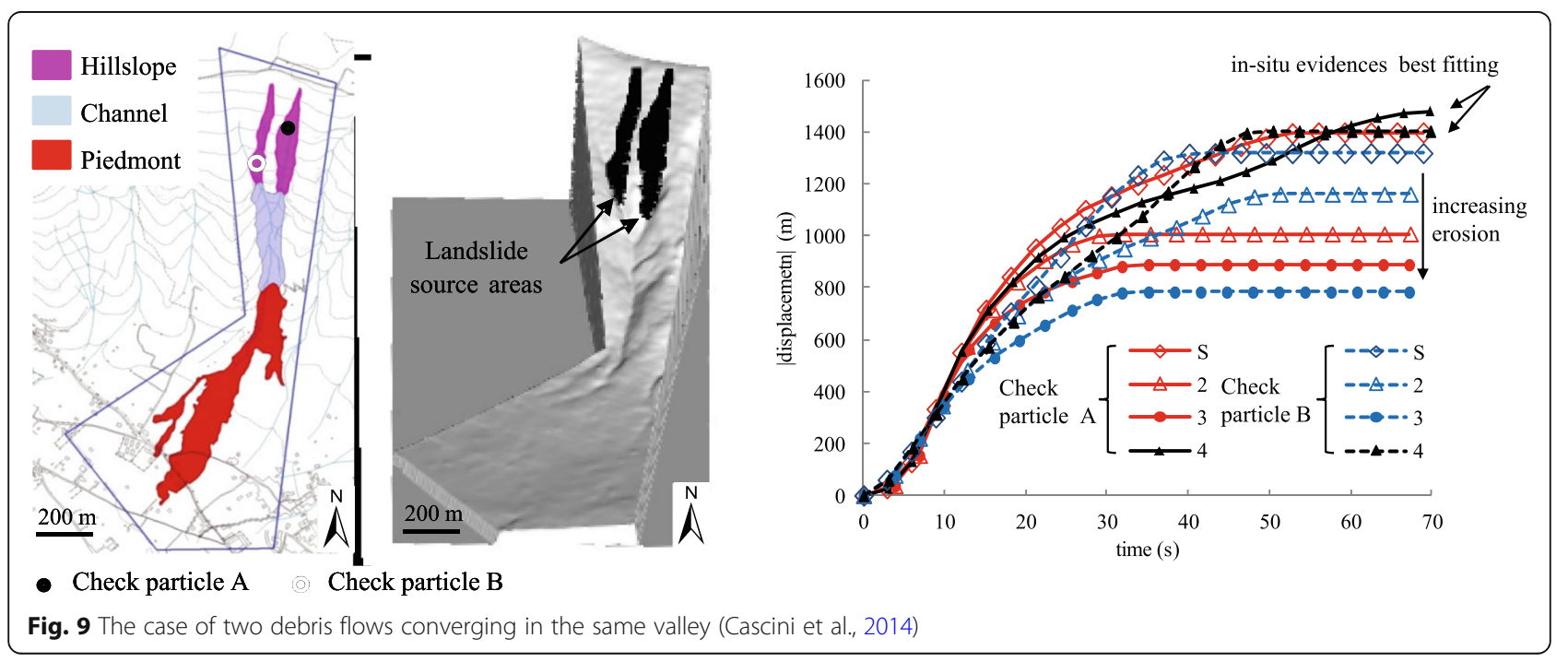



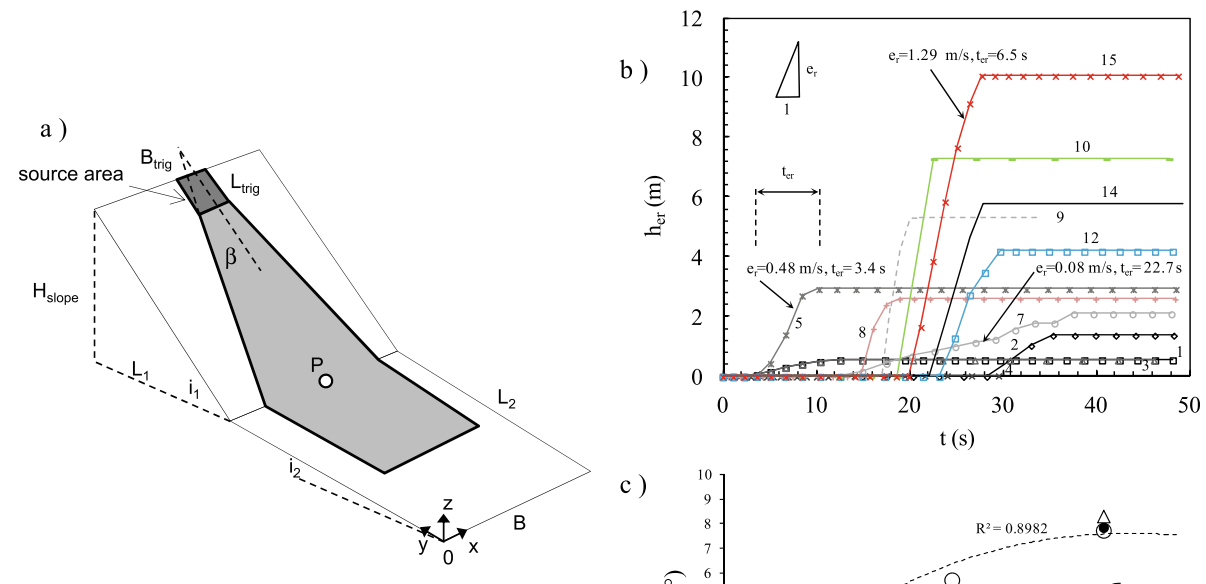

c)

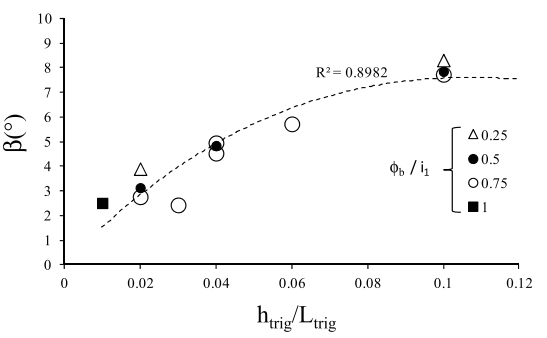

Fig. 10 Schematic (a) of an open slope affected by a debris avalanche: modeled eroded thickness (b), and lateral spreading (c) (Cuomo et al., 2014)

indicate that the greater the ratio of the triggering soil height to the length of the source area $\left(h_{\text {trig }} / L_{\text {trig }}\right)$, the greater the lateral spreading $(\beta)$, with a maximum of $8.3^{\circ}$. The $8.3^{\circ}$ maximum corresponds to a triggering soil

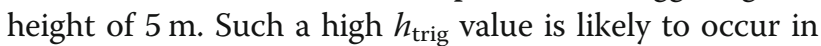
Zone 2 of the slope shown in Fig. 2 due to the impact of material falling from a bedrock scarp.

Figure 10 provides an example of these results with $L_{\text {trig }}, B_{\text {trig }}, \phi_{\mathrm{b}}, \mathrm{c}_{\mathrm{v}}$ and $E_{\mathrm{r}}$ fixed at $50 \mathrm{~m}, 40 \mathrm{~m}, 10.2^{\circ}, 0.01$ $\mathrm{m}^{2} / \mathrm{s}$ and $8.2 \times 10^{-3} \mathrm{~m}^{-1}$, respectively. The semi-apical angle $(\beta)$ increases from 1.3 to $5.2^{\circ}$ until the ratio $B_{\text {trig }} /$ $L_{\text {trig }}$ reaches 0.5 , and then $\beta$ reduces to a minimum value of $3.2^{\circ}$, independent of relative pore water pressure $\left(p_{\mathrm{w}}{ }^{\text {rel }}\right)$.

It is also worth showing the time trend in simulated eroded depths at point 'P', at the boundary between slope and piedmont. The final eroded depths $\left(h_{\mathrm{er}}\right)$ range from $1 \mathrm{~m}$ to $10 \mathrm{~m}$, with an erosion rate $\left(e_{\mathrm{r}}\right)$ ranging from 0.08 to $1.29 \mathrm{~m} / \mathrm{s}$, and an erosion time $\left(t_{\mathrm{er}}\right.$, defined as the time in which bed entrainment occurs at a given point of the slope) ranging from 3.4 to $22.7 \mathrm{~s}$. The eroded depths simulated at the boundary between slope and piedmont show two key characteristics: (i) they are the product of a combination of slope morphology, features of the triggering area, rheology and bed entrainment; and (ii) they range between 0.03 and $10.07 \mathrm{~m}$ for a wide array of debris avalanches in coarse-grained soils. Therefore, the results of the benchmark cases facilitate assessing the roles and interplay of entrainment, rheology and pore water pressure, and provide theoretical values for apical angle $(\beta)$, erosion rate $\left(e_{\mathrm{r}}\right)$, eroded depth $\left(h_{\mathrm{er}}\right)$ and erosion time $\left(t_{\mathrm{er}}\right)$ in highly idealised cases. Using these results, the analysis of relevant case histories in the following sections can be approached with confidence.

A debris avalanche triggered at the uppermost part of a hillslope may propagate into a well established channel or even spread into two or more valleys. The latter case is recorded on 5 May 1998 at the Pizzo d'Alvano massif (about $1000 \mathrm{~m}$ high), in the Cortadonica basin. A debris avalanche is triggered at $745 \mathrm{~m}$ a.s.l., enlarged along the hillslope at a semi-apical angle $(\beta)$ of about $7^{\circ}$, travelled for $510 \mathrm{~m}$, then divided in two wide valleys. It propagated over a total run-out distance of $1.95 \mathrm{~km}$ up to the piedmont area at $65 \mathrm{~m}$ a.s.l. The numerical analysis of this case is performed using a $3 \times 3 \mathrm{~m}$ Digital Elevation Model. The topography is reproduced by means of a mesh of 35,520 squares. The initial mass is schematised into a set of $639 \mathrm{SPH}$ points, $1 \mathrm{~m}$ spaced, with a uniform soil height of 1-2 $\mathrm{m}$ over the impact zone (data from Cascini et al., 2008). A frictional model is used to analyse the rheological behaviour of the unstable mass, based on the rheological parameters used by Pastor et al. (2009) to back-analyse an important channelised landslide that occurred during the May 1998 event in a neighbouring mountain basin. The landslide growth rate is assumed to be in the range $1.3 \times 10^{-4} \div 8.2 \times 10^{-2}$, which is similar to the rate of the Nocera Inferiore landslide, due to important similarities between either morphometric hillslope features or soil mechanical parameters in the two areas under study (Cascini et al., 2013a).

The results shown in Fig. 11 provide a satisfactory simulation of the observed behaviour of the landslide, 

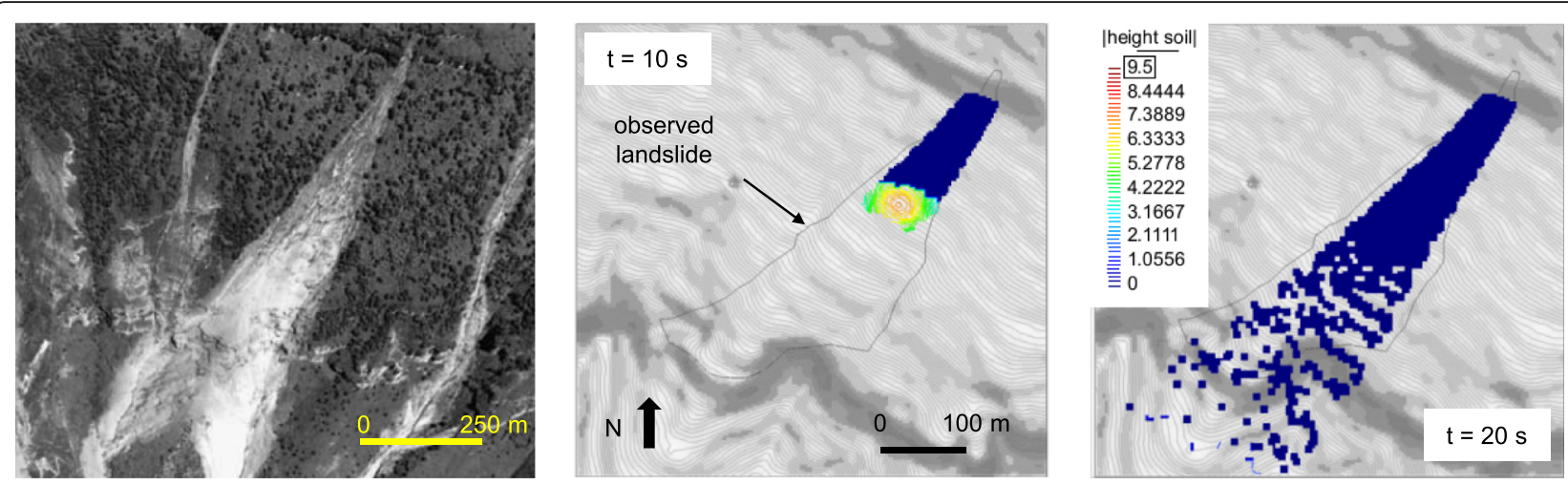

Fig. 11 Modelling of the propagation height of a debris avalanche at different time lapses for the case history of Cortadonica catchment (Italy) (Cascini et al., 2013a)

especially in terms of the lateral boundary of the debris avalanche and the splitting of its initial mass into two channels. The estimated landslide growth rate is $4.0 \times$ $10^{-3}$. The simulated erosion rate $\left(e_{\mathrm{r}}\right)$ is $0.57 \mathrm{~m} / \mathrm{s}$ and the simulated erosion time $\left(t_{\mathrm{er}}\right)$ is $2.5 \mathrm{~s}$. All of the results achieved for the Cortadonica debris avalanche show that the greater the friction angle or erosion growth rate, the higher the simulated eroded heights $\left(h_{\mathrm{er}}\right)$; similarly, if the consolidation coefficient $\left(c_{\mathrm{v}}\right)$ increases, the depth of erosion increases. Moreover, it is shown that bed entrainment decreases if the water-table height increases $\left(h_{\mathrm{w}}{ }^{\mathrm{rel}}\right)$. These results are consistent with those obtained for the previous benchmark cases and other case histories.

\section{Modelling the propagation stage of combined flows}

Different types of flows can occur in nearby locations and nearly at the same time, so that multiple soil volumes can join and propagate together. The numerical modelling is here conducted for a series of very small $\left(1088 \mathrm{~m}^{3}\right)$ to medium-sized $\left(11,630 \mathrm{~m}^{3}\right)$ landslides. They were recorded at Bracigliano site, approximately at 2 p.m. on May 5, 1998, along the hills to the northwest of town (Monte Faitaldo and Monte Foresta), where the largest landslide occurred (950 $\mathrm{m}$ a.s.l.). Different triggering mechanisms and types of source areas are identified by Cascini et al. (2008), including the following: $M 1$, colluvial hollows with convergent sub-superficial groundwater circulation and temporary springs from bedrock; $M 2$, triangular areas at open slopes associated with outcropping or buried bedrock scarps; $M 6$, areas shaped like short and thick spoons situated at either the base of the convex-concave hillslopes or along the flanks of the inner gorges. Among these different source areas, Cascini et al. (2013a) identified two debris avalanches. The source areas are generally at elevations between 800 and $900 \mathrm{~m}$, and slope failures involved, in some cases, the entire thickness of the pyroclastic cover. The numerous detachments induced debris flows that converged in one main gully, exiting in urban roads and causing loss of life and widespread damage to buildings. The flows reached high water content owing to the runoff along the channels and urban roads: this explains the unusually large shape of the deposition zone and the long run-out distance of the flow, which reached the near city of Siano. The rheological properties and bed entrainment rate $(K)$ are calibrated to best fit the extent of the propagation area, from the uppermost slopes to the urbanized area located at the piedmont. Here, a dense network of paved roads and narrow streets is present, and an adequate modelling of landslide propagation would require a finer DTM and, for instance, very accurate specific information about the hydraulic works; this is certainly beyond the scope of this paper. Particularly, the attention is focused on the upper part of the right-hand side of Monte Foresta, where 2 debris avalanches (M2) and 9 debris flows (M1) were triggered between 800 and $900 \mathrm{~m}$ a.s.l.. In fact, the eyewitnesses and in situ evidence shows that from the left-hand side of the catchment, a flood arrived, which caused the enlargement of the landslide body within the urban zone.

The numerical analyses are based on a DTM of 939, 330 squares, each $3 \times 3 \mathrm{~m}$ in size. The 11 unstable masses are schematized into 11 sets of SPH computational points for a total of 2905 points. The initial soil height in source areas is $2.5 \mathrm{~m}$ or $1.5 \mathrm{~m}$, depending on the triggering mechanisms $\mathrm{M} 1$ and $\mathrm{M} 2$, respectively. The rheological parameters are the same as those chosen for the numerical simulations of the Cortadonica catchment, owing to the proximity of the two sites and to compare the results. Two opposite results are simulated (Fig. 12): a) the landslides do not reach the piedmont, if the water table height in the source areas $\left(h_{\mathrm{w}}{ }^{\text {rel }}\right)$ is assumed to be lower than 0.4 or if the bed entrainment rate $(K)$ is higher than 0.007 ; b) the landslide overcomes the left-hand side boundary of the propagation path if 


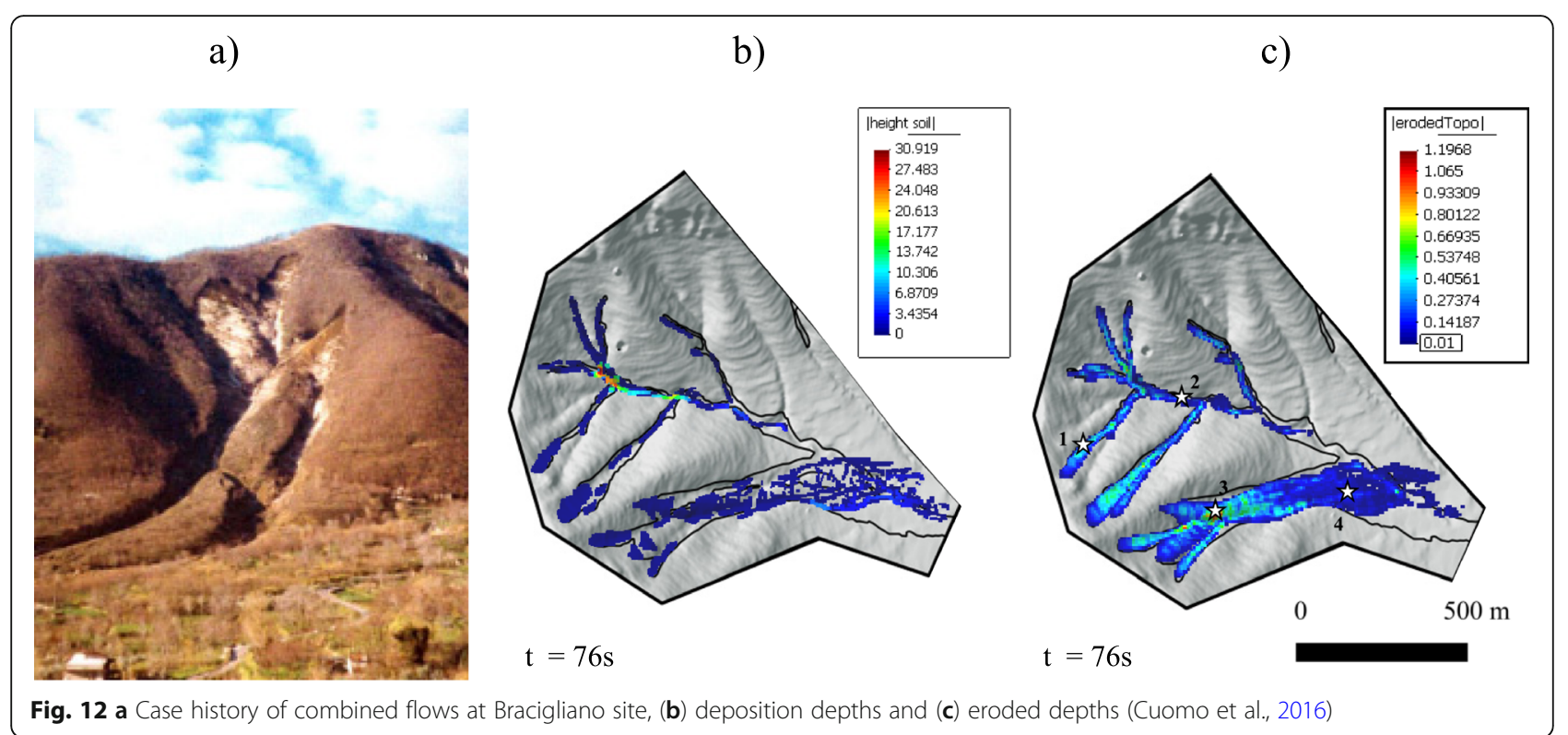

$h_{\mathrm{w}}{ }^{\text {rel }}$ is higher than 0.4 or $K$ is lower than 0.007 . This entails that $h_{\mathrm{w}}{ }^{\text {rel }}=0.4$ and $K=0.007$ are found to be the best-fitting values for the propagation back-analysis of the event. In addition, $\tan \left(\phi_{\mathrm{b}}\right), p_{\mathrm{w}}{ }^{\text {rel }}$ and $c_{\mathrm{v}}$ are the same as the nearby Cortadonica catchment. This is also a consistency check of the parameters used for rheology and bed entrainment at the three sites.

Particularly, the simulated propagation heights shown in Fig. 13 reproduce quite well the landslide lateral boundaries and the path observed in the field, with all masses propagating in distinct channels and stopping at the uppermost boundary of the urban area. It is also important to note that the eroded thicknesses have high spatial variation (Fig. 12), with the maximum erosion depth simulated at the right-hand side of the boundary of the catchment, as observed in situ. As in the previous cases, the simulated entrainment increases when moving from the top to the toe of the massif, but then entrainment drastically decreases where steepness diminishes. In fact, a lower slope angle has a direct effect on reducing the bed entrainment and also an indirect effect because a lower slope angle favours the lateral spreading of

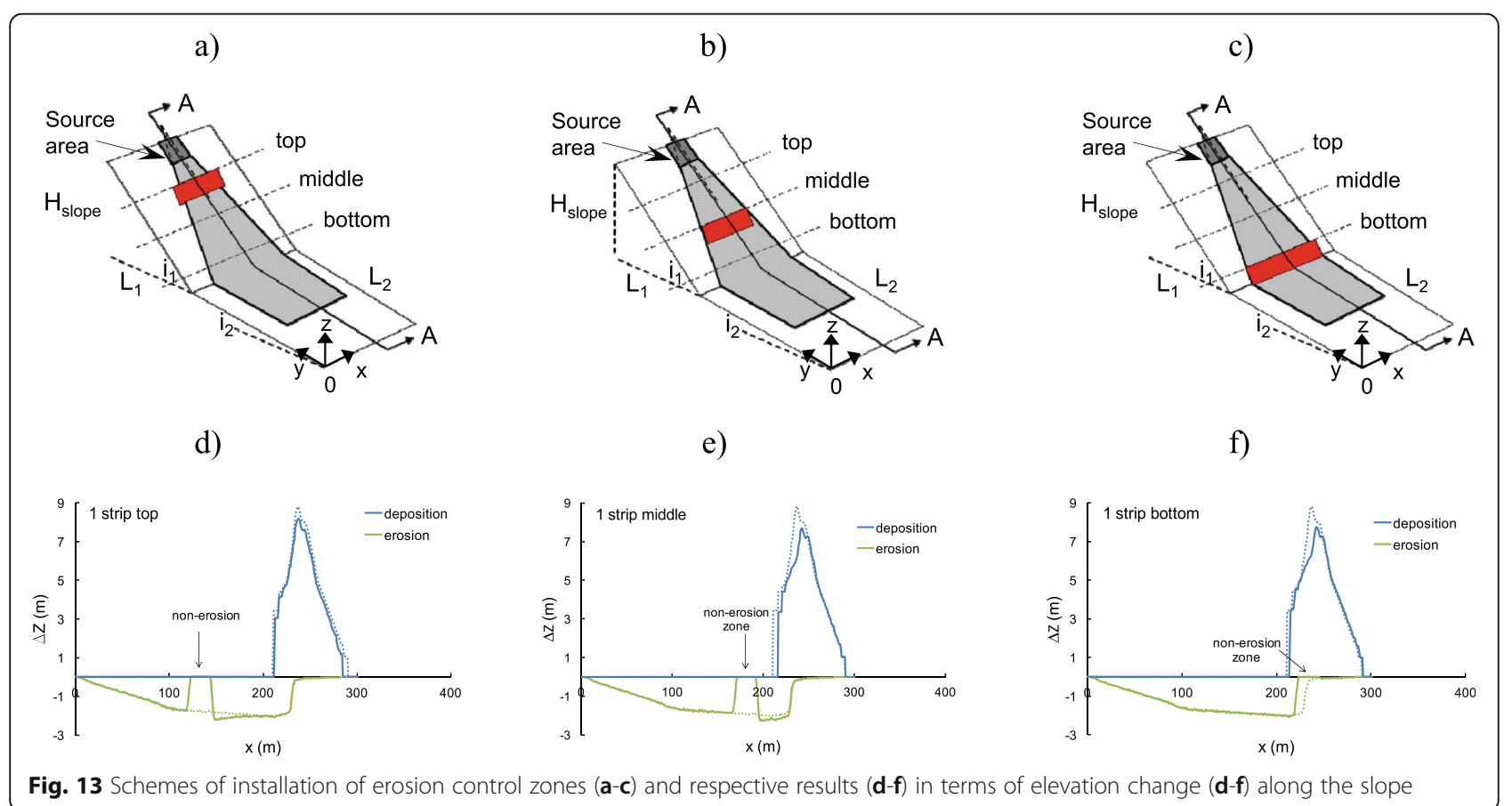


flow - as shown in Cuomo et al., 2014) - and causes a general reduction in the propagation heights, which once again diminishes the bed entrainment. Finally, it is worth noting that the plots of $h_{\mathrm{er}}$ versus $t-t_{\text {flow }}$ (Fig. 12) are inconsistent with the values $\left(0.08 \mathrm{~m} / \mathrm{s}<e_{\mathrm{r}}<1.29 \mathrm{~m} / \mathrm{s}\right)$ indicated by Cuomo et al. (2014) for DAs; this is clearly because the simulated events are a combination of several DFs and two DAs.

\section{Results and discussion for engineered slopes Analysis of the effect of erosion control}

One potential solution to reduce the volume of debris avalanches is represented by the construction of erosion control installation. The desired effect is to eliminate the bed entrainment at designed locations. Several analyses are carried on a schematic open slope, consisting of two planes with inclines to the horizon $i_{1}$ and $i_{2}$, respectively (Fig. 13). Different arrangements of non-erodible zone are considered. Three relevant combinations are proposed for the numerical simulations, as those depicted in Fig. 13. In all the cases, inside a non-erodible zone, large as the distance from the uppermost baffle to the lowermost one, the prevention of entrainment is guaranteed. On the other hand, the overall benefit and the eventual side effects are here evaluated through the numerical modeling.

The source area is located at the uppermost edge of the upper slope. The numerical analysis are performed using a $1 \mathrm{~m} \times 1 \mathrm{~m}$ Digital Terrain Model (DTM). The initial mass is schematized into a set of $544 \mathrm{SPH}$ points, $1 \mathrm{~m}$ spaced, with a uniform soil thickness of $1 \mathrm{~m}$ over the failure zone. A frictional rheological model is used with parameters taken from literature $\left(\tan \phi_{\mathrm{b}}=0.5\right.$, $\left.h_{\mathrm{w}}{ }^{\mathrm{rel}}=0.4, p_{\mathrm{w}}{ }^{\mathrm{rel}}=0.5, c_{\mathrm{v}}=10^{-2} \mathrm{~m}^{2} \mathrm{~s}^{-1}, K=0.03\right)$. A sensitivity analysis is also conducted changing both the slope inclination $\left(30-40^{\circ}\right)$ and the initial volume (500, $5000,10,000$ or $\left.15,000 \mathrm{~m}^{3}\right)$.

In order to quantify the reduction in the eroded soil thickness, a longitudinal section is represented (Fig. 13), where we can see the longitudinal profile of the slope before and after the flow propagated, with also the erosion heights represented. The entrainment rate $(\Delta \mathrm{z} / \mathrm{x})$ is almost the same upslope and downslope the erosion control areas. It means that the landslide dynamic is poorly modified. This is observed in all the combinations. The erosion control has major local effect while smaller general consequence on the landslide.

Based on that, one can say that the higher the extent of the non-erodible areas, the higher the benefit of this countermeasure, as the volume reduction relates exclusively to the extent of the treated area. Of course, the closer the intervention is to the toe of the slope, the less is the erosion, as the faster is the landslide when it reaches the control work. This last observation is valid for the examined cases of relatively "short" slopes, some $300-400 \mathrm{~m}$ long. The benefit in terms of volume reduction is negligible for small-medium sized landslides, and does not exceed the $18 \%$ for the biggest ones here considered.

\section{Modelling the benefits of artificial baffles}

Other types of control works are more focused to change the dynamics of flow propagation. The destructiveness of a debris avalanche can be mitigated, for instance, by obstacles along the flow path as they can slow or even stop the flow. This kind of obstacles can be natural, for example big trees or boulders, or artificial such as rigid or flexible barriers, or concrete columns known as baffles. Along the flow path two rows of rectangular obstacles have been positioned. Different combinations of these obstacles changing both disposition and position are considered. The presence of the obstacles is taken into account in the simulation by considering nil normal velocity along the obstacle boundaries. The same rheological properties of the previous section are here considered.

The first analysis is carried out to understand how these obstacles and their position can change the dynamics of the debris avalanche. Referring to the schematic slopes of Fig. 14, three different cases are analysed different for the distance of the obstacles from the source area $(L)$. We will have, therefore, the first case with the obstacles in the upper zone of the slope (Fig. 14a), the second one with the obstacles in the middle of the slope (Fig. 14c) and in the final case they are positioned near the break of the slope (Fig. 14d). Moreover for the first case, a reverse position of the obstacles is also analysed, with two obstacles in the first row impacted and three in the second one (Fig. 14b).

The installation of the baffles highly changes i) the eroded depths along the slope, ii) the runout and, iii) the final deposition thicknesses. Regarding the former issue, it is worth noting that the debris avalanche entrains material at a nearly constant rate $(\Delta \mathrm{z} / \mathrm{x})$ in the upper part of the slope. Then, a drastic reduction of entrainment occurs at the baffle location, as expected. More interestingly, the debris avalanche starts to entrain material again downslope the baffles. The material is entrained at a lower rate downslope (i.e. after the interaction with) the baffles. It means that the baffles completely modify the dynamics of landslide as desired. Of course, this drastic change would be positive in case the runout and deposition at the toe of the slope are both reduced. Such expectations are confirmed in Fig. 15. The runout is decreased and some of the soil volume is trapped behind the barrier for any baffle combination.

The decrease of velocity due to the impact of the flow on the obstacles, the anti-erosion effect and the capacity 
a)

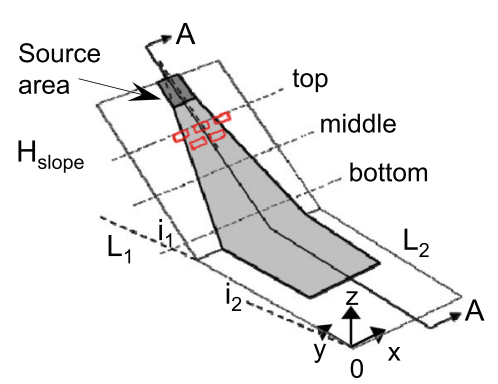

c)

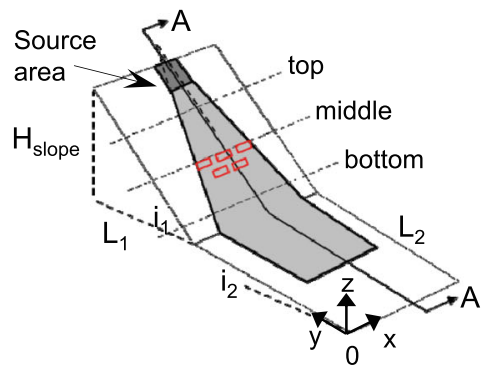

b)

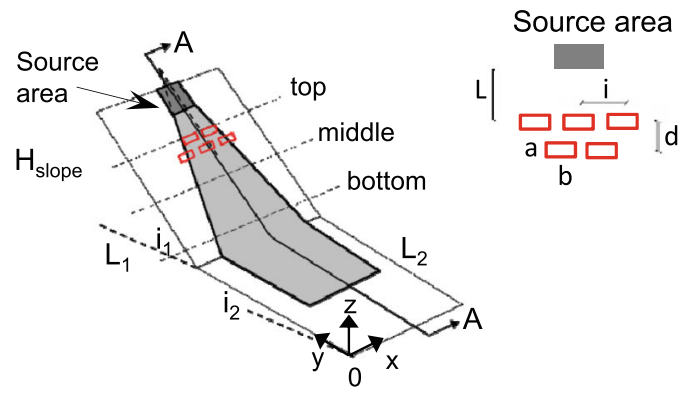

d)

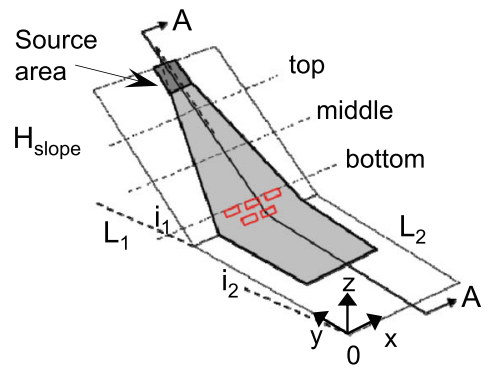

Fig. 14 Different configurations (a-d) of multiple artificial baffles along an open slope

of the obstacles to contain part of the flow, permit a reduction in the final mobilised volume. To evaluate this issue, the amplification factor $A_{\mathrm{f}}$ is introduced as the rate of the final mobilised volume $\left(V_{\mathrm{f}}\right)$ to the initial volume $\left(V_{\mathrm{i}}\right)$.

The landslide cumulated volume is plotted versus and also the final amplification factor is reported (Fig. 16), so that it is possible evaluating how much the landslide increases in different cases, and compared with natural slope (without obstacles).

\section{Analysis of artificial barriers installed at the piedmont areas}

In combination or as an alternative to the previous mitigation works, a barrier installed at the toe of the slope can be considered. A schematic open slope is firstly analysed, which is composed of two differently inclined planes and a debris avalanche triggered at the uppermost portion of the slope. The computational scheme and the soil properties are taken from Cuomo et al. (2014), who extensively investigated the role of the several factors involved in the propagation stage of a debris avalanche.

The slopes are inclined at $30^{\circ}$ or $40^{\circ}$ with different lengths (horizontal projection) $L_{1}$ (Fig. 17). The piedmont zone is flat or gently inclined ( $10^{\circ}$ steep) with length $L_{2}$. The length and the width of the source area are $L_{\text {trig }}$ and $B_{\text {trig, }}$, respectively, and $H_{\text {trig }}$ is the initial height of soil inside the source area. A selection of the several numerical simulations are with $L_{1}=230 \mathrm{~m}, L_{2}=$
$500 \mathrm{~m}$, the width of the slope $(B)$ equal to $800 \mathrm{~m}$, and the slope height $\left(\mathrm{H}_{\text {slope }}\right)$ equal to $222 \mathrm{~m}$ or $130 \mathrm{~m}$ for $\alpha_{P}=10^{\circ}$ or $\alpha_{P}=0^{\circ}$, respectively. The DTM cell size is equal to $1.1 \mathrm{~m}$ for both slopes, inclined with $40^{\circ}$ and $30^{\circ}$. One or more barriers are added in the piedmont zone. Each barrier is $5 \mathrm{~m}$ high $(H)$, with top width $(b)$ equal to $3 \mathrm{~m}$, the upslope raceway (a) $3 \mathrm{~m}$ wide, and both lateral scarps inclined at $60^{\circ}$. The Type I barrier has a trapezoidal shape; the Type II barrier is similar but with an additional step ( $H / 2$ high, and large as $b)$ located upslope. In the simulations, the first barrier is in the piedmont zone, specifically $10 \mathrm{~m}(\mathrm{x}=240 \mathrm{~m})$ or $25 \mathrm{~m}(\mathrm{x}=$ $255 \mathrm{~m})$ or $50 \mathrm{~m}(\mathrm{x}=280 \mathrm{~m})$ downslope the divide between the slope and the piedmont.

Different sets of soil properties, such as the soil unit weight $(\gamma)$, the friction angle $\left(\tan \phi_{\mathrm{b}}=0.30\right.$ or 0.52 ), the initial height of water table divided by the soil thickness $\left(h_{w}{ }^{\text {rel }}=0.40\right.$ or 0.75$)$, the initial value of relative pore water pressure $\left(p_{\mathrm{w}}{ }^{\text {rel }}=0.5\right.$ or 1.0$)$, the dimensions of the source area $\left(L_{\text {trig }}=25 \mathrm{~m}\right.$ or $100 \mathrm{~m}$; $B_{\text {trig }}=10 \mathrm{~m}$ or $50 \mathrm{~m}$ ), and the initial height of the flow $\left(h_{\text {trig }}=1.0\right.$ or $\left.4.0 \mathrm{~m}\right)$ are taken from Cuomo et al. (2014), resembling the features of catastrophic events that occurred in Southern Italy, such as those of Cervinara in 1999 (Cascini et al., 2011a), and Nocera Inferiore in 2005 (Cuomo et al., 2014).

The computational points are initially spaced $1.1 \mathrm{~m}$ and the time step is $0.5 \mathrm{~s}$. Two parameters are referred for the flow propagation analysis, namely the Index of 

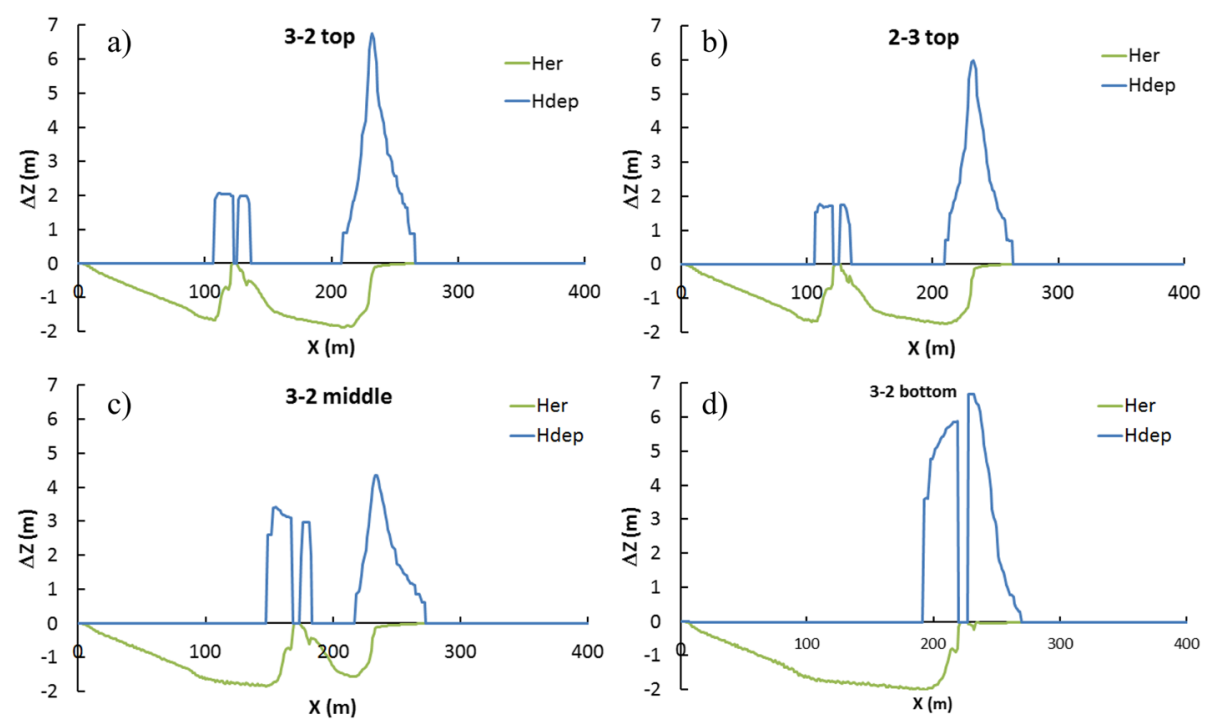

Fig. 15 Effects (a-d) of the artificial baffles on the eroded and deposition depths along an open slope

Piedmont Runout Reduction $\left(\mathrm{I}_{\mathrm{PRR}}\right)$ and the Index of Lateral Spreading $\left(\mathrm{I}_{\mathrm{LS}}\right)$, which read as: $I_{\mathrm{PRR}}=P R_{\mathrm{eng}} / P R_{\text {nat }}$, $I_{\mathrm{LS}}=W_{\text {eng }} / W_{\text {nat }}$, where $P R_{\text {eng }}$ is the Piedmont Runout distance travelled by the flow inside the piedmont zone engineered with barriers, $P R_{\text {nat }}$ is the runout inside the piedmont zone for the natural slope, $W_{\text {eng }}$ is the maximum lateral width of the flow behind the barrier for the engineered slope, and $W_{\text {nat }}$ is the analogous feature of the flow computed at the same point for the natural slope.

A value of $I_{P R R}<1.0$ is desirable, and the lower $I_{P R R}$, the better the efficiency of the barrier. $\mathrm{I}_{\mathrm{PRR}}$ also depends on where the barriers are located. A barrier favours the flow material to spread laterally and it is expected that $\mathrm{I}_{\mathrm{LS}}>1.0$. For multiple barriers, $\mathrm{I}_{\mathrm{LS}}$ is computed with the highest $\mathrm{W}_{\text {eng }}$ obtained for each barrier. The computed values of $I_{\mathrm{PRR}}$ and $I_{\mathrm{LS}}$ are reported in Fig. 18 for all cases. Four zones can be individuated in the plots: 1) $I_{\mathrm{PRR}}<1.0$ and $I_{\mathrm{LS}}<1.0$, i.e. both the runout and the width decrease,

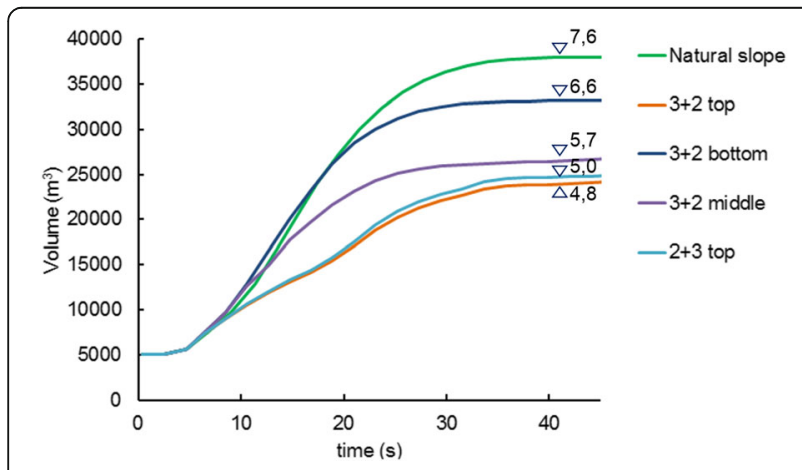

Fig. 16 Landslide volume amplification for a natural slope and another equipped with baffles meaning that the barrier is effective. This is an unlikely condition; 2) $\mathrm{I}_{\mathrm{PRR}}<1.0$ and $\mathrm{I}_{\mathrm{LS}}>1.0$, i.e. the runout diminishes while the width increases, meaning the barrier is still effective. This is a very likely condition; 3) $I_{P R R}>$ 1.0 and $\mathrm{I}_{\mathrm{LS}}>1.0$, i.e. both runout and the width increase and thus the barrier is ineffective in terms of reduction of runout; 4) $\mathrm{I}_{\mathrm{PRR}}>1.0$ and $\mathrm{I}_{\mathrm{LS}}<1.0$, i.e. there is a reduction of width and an increase of runout, so that the barrier is ineffective. However, this condition is unrealistic. For two barriers, we considered the maximum width of flow in the plane-view. The computed runout is always reduced with one or two barriers, irrespective of overtopping. In general, runout can be reduced to 70\% (Case S3) with a maximum increase of lateral spreading of $5 \%$ compared to the natural slope. Furthermore, the barrier type differently influences the area affected by the flow. In particular, $I_{\text {PRR }}$ decreases, passing from Type I to Type II for the same position of the barriers (Case S4 and Case S5, or Case R17 and Case R18). The barrier type does not influence $I_{\text {PRR }}$ for barriers located very far from the landslide source area (Cases S6 and S7, R24 and R25).

\section{Conclusions}

Numerical modelling is a powerful tool to understand and forecast heights and velocities, given that all these variables change very rapidly and are spatially distributed. This is even truer considering that unrevealed propagation patterns have been observed in real case histories and small-scaled laboratory experiments. Notwithstanding the complexity of flow-like landslides and the related challenges for modelling, the understanding and forecasting of such natural hazards is achievable with a satisfactory confidence. 


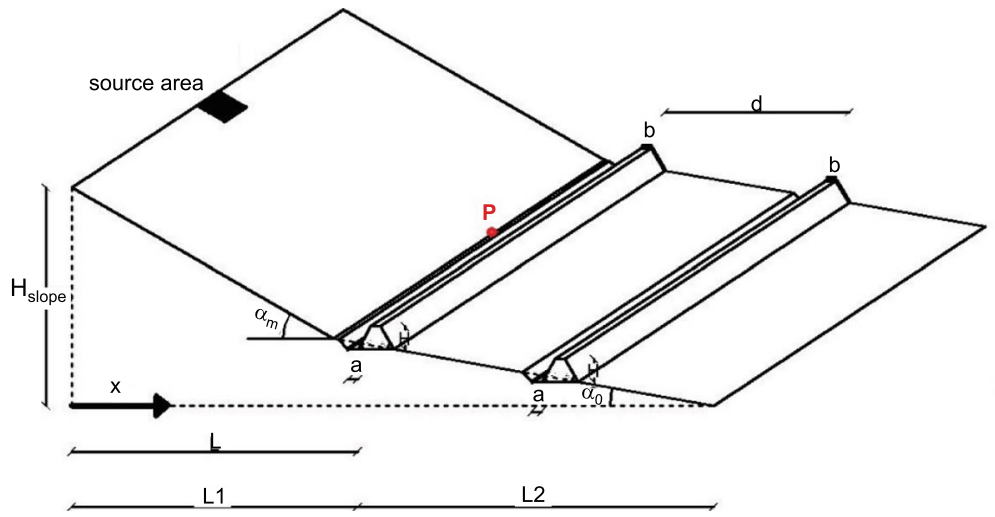

a)

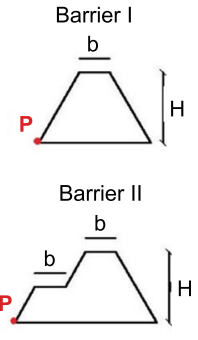

b)

Fig. 17 Scheme of the artificial barriers considered at the toe of the slope: a) overview, b) cross sections (Cuomo et al., 2019c)

Among the key factors, rainfall, pore water pressure and bed entrainment deserves a special attention. Thus, the paper provided a number of examples regarding that. Further improvements are expectable as the numerical models are becoming more efficient. Thus, more accurate descriptions of local effects will be possible and also additional mechanisms will be possibly analysed.

On the other hand, control works and engineering countermeasures represent one option for risk mitigation and disasters reduction. In this sense, intervention along the slopes or at the piedmont areas may be conceived depending on many other aspects such as, for instance, the feasibility of concrete structures, the costs, and the acceptance of resident populations. The paper compares three mitigation options in a relatively small set of simplified cases. More investigation could be useful to generalize the range of mitigation opportunities also for real case histories.

More in general, the recent increased understanding of those tremendous hazards, and the availability of accurate simulation instruments should also increase the awareness of specialists and populations about the fact that the mitigation of geoenvironmental disasters is not an optional topic to be considered, but a fundamental issue to be mandatorily tacked by the new generations.
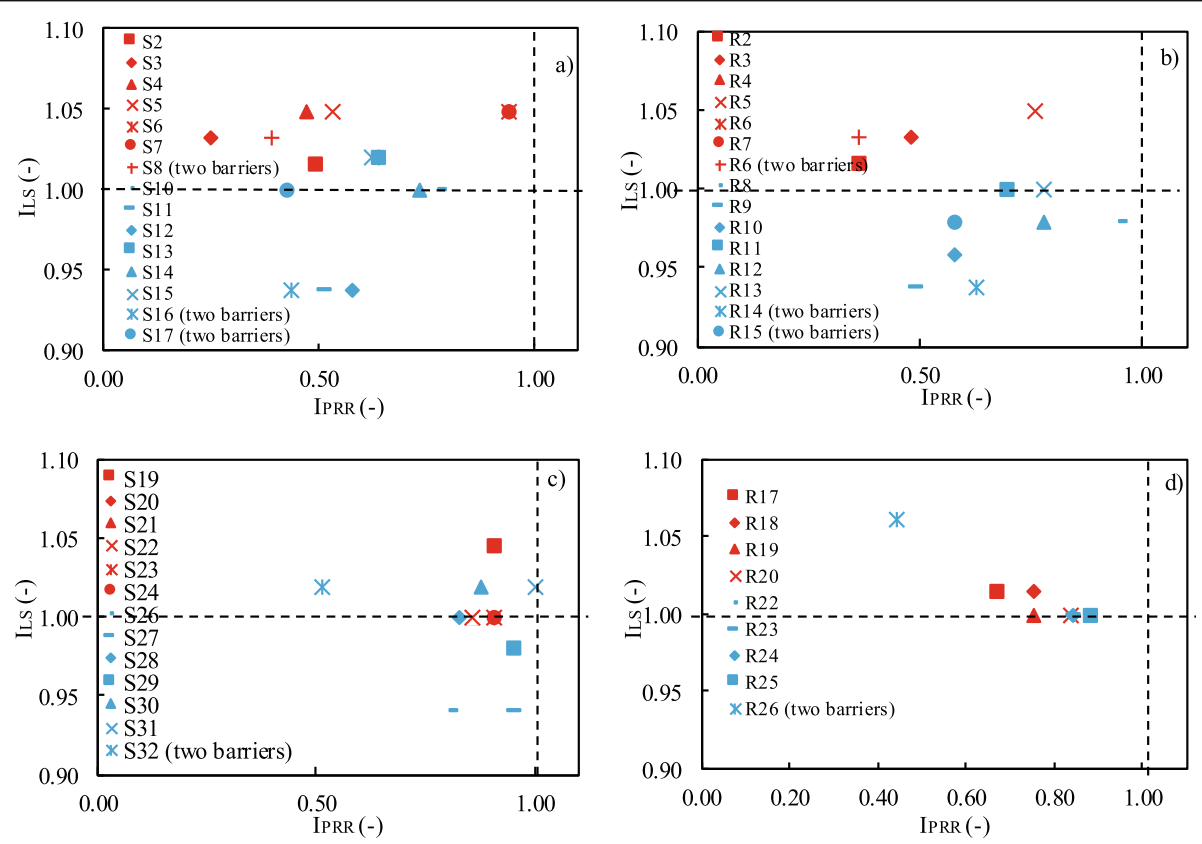

Fig. 18 Effects of artificial barriers on Piedmont Runout Reduction (l PRR $)$ and Lateral Spreading (ILS) (Cuomo et al., 2019C) 


\section{Abbreviations}

ALE: Arbitrary Lagrangian Eulerian method; c': effective cohesion; $c_{v}$ : consolidation coefficient; DA: Debris Avalanche; DEM: Discrete Element Method; DF: Debris Flow; $E_{r}$ : erosion coefficient; $e_{r}$ : entrainment rate; FEM: Finite Element Method; FEMLIP: Finite Element Method with Lagrangian Integration Point; $h$ : flow depth; $h_{w}{ }^{\text {rel }}$ : height of water table normalized to soil thicknees; $K$ : bed entrainment parameter; $k_{\text {sat }}$ : saturated conductivity; LEM: Limit Equilibrium Methods; MPM: Material Point Method; $n$ : porosity; $p^{\prime}$ : effective isotropic stress; $p^{b}$ : basal pore water pressure; $p_{\mathrm{w}}{ }^{\text {rel }}$ : ratio of pore water pressure to liquefaction pressure; $q$ : deviatoric stress; s: suction; SPH: Smoothed Particles Hydrodynamics; $S_{r}$ : saturation degree; $v$ : flow velocity; $\gamma_{\text {sat }}$ : saturated unit weight; $\varphi^{\prime}$ : friction angle; $\varphi_{\mathrm{b}}$ : basal friction angle

\section{Acknowledgements}

Prof. Manuel Pastor (Universidad Politecnica de Madrid, Spain) and coworkers are much acknowledged for precious suggestions and fruitful cooperation and also for having provided the "GeHoMadrid" code and the "GeoFlow_SPH" code used for the numerical simulations. The results shown in the paper comes from a long-lasting research developed by the Geotechnical Engineering Group (GEG) of University of Salerno. Fundamental contributions were given over the years by Prof. Leonardo Cascini, Prof. Giuseppe Sorbino, Dr. Luca Piciullo, Dr. Vittoria Capobianco, Dr. Ilaria Rendina, Eng. Giuseppe Claudio Castorino and Eng. Stefano Petrosino.

\section{Availability of data and supporting materials}

Please contact author for data requests.

\section{Authors' contributions}

Sabatino Cuomo is responsible for the data collection, numerical modelling and the corresponding passages in the manuscript. The author read and approved the final manuscript.

\section{Funding}

The research was supported by a number of Italian Research Projects funded by the Italian Education and Research Ministry such as: Project FARB 2017 "Numerical modelling and inverse analysis for flow-like landslides"; Project FARB 2014 "Large area analysis of triggering and propagation landslide susceptibility for flow-like landslides"; Project FARB 2012 "New Frontiers of advanced numerical simulation of destructive landslides".

\section{Competing interests}

I hereby declare that I have any competing financial interests.

Received: 27 February 2019 Accepted: 11 October 2019

Published online: 06 January 2020

\section{References}

Alonso, E., A. Gens, A. Lloret, and C. Delahaye. 1996. Effect of rain infiltration on the stability of slopes, 241-249. Paris: Alonso \& Delage eds.

Anderson, A., and N. Sitar. 1995. Analysis of rainfall-induced debris flow. Journal of Geotechnical Engineering 121 (7): 544-552.

Anderson, S.A., and M.F. Riemer. 1995. Collapse of saturated soil due to reduction in confinement. Journal of Geotechincal Engineering ASCE 121 (2): 216-220.

Bilotta, E., V. Foresta, and G. Migliaro. 2006. Suction controlled laboratory tests on undisturbed pyroclastic soil: Stiffnesses and volumetric deformations. In Proc. international conference on unsaturated soils, 2-6 April, carefree, Arizona USA, 1, 849-860.

Blanc, T. 2011. A SPH depth integrated model with pore pressure coupling for fast landslides and related phenomena. PhD Thesis (Madrid), 292.

Blanc, T., and M. Pastor. 2011. A stabilized Smoothed Particle Hydrodynamics, Taylor-Galerkin algorithm for soil dynamics problems. International Journal for Numerical and Analytical Methods in Geomechanics Published online in Wiley Online Library (wileyonlinelibrary.com). https://doi.org/10.1002/nag.1082.

Blanc, T., and M. Pastor. 2012a. A stabilized Runge Kutta, Taylor smoothed particle hydrodynamics algorithm for large deformation problems in dynamics. International Journal for Numerical Methods in Engineering 91 (issue 13): $1427-1458$

Blanc, T., and M. Pastor. 2012b. A stabilized fractional step, Runge Kutta Taylor $\mathrm{SPH}$ algorithm for coupled problems in Geomechanics. Computer Methods in Applied Mechanics and Engineering 221 (222): 41-53.
Blanc, T., M. Pastor, V. Drempetic, and B. Haddad. 2011. Depth integrated modelling of fast landslides propagation. European Journal of Environmental and Civil Engineering 15: 51-72.

Braun, A., S. Cuomo, S. Petrosino, X. Wang, and L. Zhang. 2018. Numerical SPH analysis of debris flow run-out and related river damming scenarios for a local case study in SW China. Landslides 15 (3): 535-550.

Braun, A., X. Wang, S. Petrosino, and S. Cuomo. 2017. SPH propagation backanalysis of Baishuihe landslide in south-western China. Geoenvironmental Disasters 4 (1): 2

Brufau, P., P. Garcì-Navarro, P. Ghilardi, L. Natale, and F. Savi. 2000. 1D mathematical modelling of debris flow. Journal Rech Hydraul 38: 435-446.

Cascini, L. 2004. The flowslides of may 1998 in the Campania region, Italy: The scientific emergency management. Italian Geotechnical Journal 2: 11-44.

Cascini, L., S. Cuomo, and A. De Santis. 2011a. Numerical modelling of the December 1999 Cervinara flow-like mass movements (Southern Italy). Italian Journal of Engineering Geology and Environment: 635644.

Cascini, L., S. Cuomo, and M. Della Sala. 2011 b. Spatial and temporal occurrence of rainfall-induced shallow landslides of flow type: A case of Sarno-Quindici, Italy. Geomorphology 126: 148-158.

Cascini, L., S. Cuomo, A. Di Mauro, M. Di Natale, S. Di Nocera, and F. Matano. 2019. Multidisciplinary analysis of combined flow-like mass movements in a catchment of Southern Italy, 1-18. Georisk: Assessment and Management of Risk for Engineered Systems and Geohazards.

Cascini, L., S. Cuomo, and D. Guida. 2008. Typical source areas of May 1998 flowlike mass movements in the Campania region, Southern Italy. Engineering Geology 96 (3-4): 107-125.

Cascini, L., S. Cuomo, and M. Pastor. 2013a. Geomechanical modelling of debris avalanches inception. Landslides 10 (6): 701-711.

Cascini, L., S. Cuomo, M. Pastor, and I. Rendina. 2016. SPH-FDM propagation and pore water pressure modelling for debris flows in flume tests. Engineering Geology 213: 74-83.

Cascini, L., S. Cuomo, M. Pastor, and C. Sacco. 2013b. Modelling the post-failure stage of rainfall-induced landslides of the flow type. Canadian Geotechnical Journal 50 (9): 924-934.

Cascini, L., S. Cuomo, M. Pastor, and G. Sorbino. 2010. Modeling of rainfallinduced shallow landslides of the flow-type. Journal of Geotechnical and Geoenvironmental Engineering 136 (1): 85-98.

Cascini, L., S. Cuomo, M. Pastor, G. Sorbino, and L. Piciullo. 2014. SPH run-out modelling of channelized landslides of the flow type. Geomorphology 214: 502-513.

Cascini, L., S. Cuomo, and G. Sorbino. 2005. Flow-like mass movements in pyroclastic soils: Remarks on the modelling of triggering mechanisms. Italian Geotechnical Journal 4: 11-31.

Chen, H., G.B. Crosta, and C.F. Lee. 2006. Erosional effects on runout of fast landslides, debris flows and avalanches: A numerical investigation. Geotechnique 56: 305-322.

Chu, J., S. Leroueil, and W.K. Leong. 2003. Unstable behaviour of sand and its implications for slope instability. Canadian Geotechnical Journal 40: 873-885.

Corominas, J. 1996. The angle of reach as a mobility index for small and large landslides. Canadian Geotechnical Journal 33: 260-271.

Crosta, G.B., S. Imposimato, and D.G. Roddeman. 2009. Numerical modelling of entrainment/deposition in rock and debris-avalanches. Engineering Geology 109: 135-145.

Cuomo, S. 2006. Geomechanical modelling of triggering mechanisms for flow-like mass movements in pyroclastic soils, 274. Italy: PhD dissertation at the University of Salerno.

Cuomo, S., A. Di Perna, P. Ghasemi, M. Martinelli, and M. Calvello. 2019a. Combined LEM and MPM analyses for the simulation of a fast moving landslide in Hong Kong. In Proc. of II International Conference on the Material Point Method for modelling soil-water-structure interaction. 8-10 January 2019, University of Cambridge, UK.

Cuomo, S., P. Ghasemi, M. Martinelli, and M. Calvello. 2019b. Simulation of Liquefaction and Retrogressive Slope Failure in Loose Coarse-Grained Material. International Journal of Geomechanics 19 (10): 04019116.

Cuomo, S., S. Moretti, and S. Aversa. 2019c. Effects of artificial barriers on the propagation of debris avalanches. Landslides 16 (6): 1077-1087.

Cuomo, S., M. Moscariello, D. Manzanal, M. Pastor, and V. Foresta. 2018. Modelling the mechanical behaviour of a natural unsaturated pyroclastic soil within generalized plasticity framework. Computers and Geotechnics 99: 191-202.

Cuomo, S., M. Pastor, V. Capobianco, and L. Cascini. 2016. Modelling the spacetime evolution of bed entrainment for flow-like landslides. Engineering Geology 212: 10-20. 
Cuomo, S., M. Pastor, L. Cascini, and G.C. Castorino. 2014. Interplay of rheology and entrainment in debris avalanches: A numerical study. Canadian Geotechnical Journal 51 (11): 1318-1330.

Cuomo, S., M. Pastor, S. Vitale, and L. Cascini. 2013. Improvement of irregular DTM for SPH modelling of flow-like landslides. Proc. of XII International Conference on Computational Plasticity. Fundamentals and Applications (COMPLAS XII), E Oñate, DRJ Owen, D Peric and B Suárez. 3-5 September 2013, Barcelona, Spain. ISBN: 978-84-941531-5-0, 512-521.

Dai, F., C.F. Lee, S. Wang, and Y. Feng. 1999. Stress-strain behaviour of a loosely compacted volcanic-derived soil and its significance to rainfall-induced fill slope failures. Engineering Geology 53: 359-370.

Darve, F., and F. Laouafa. 2000. Instabilities in granular materials and application to landslides. Mechanics of Cohesive frictional Materials 5 (8): 627-652.

Duncan, J.M. 1996. State of the art: Limit equilibrium and finite element analysis of slopes. Journal of Geotechnical Engineering, ASCE 122 (7): 557-596.

Eckersley, D. 1990. Instrumented laboratory flowslides. Géotechnique 40: 489-502.

Egashira, S., N. Hondab, and T. Itohc. 2001. Experimental study on the entrainment of bed material into debris flow. Physics and Chemistry of the Earth, Part C 26: 645-650.

Egashira, S., T. Itoh, and H. Takeuchi. 2000. Transition mechanism of debris flows over rigid bed to over erodible bed. Physics and Chemistry of the Earth, Part $B$ 26: 169-174

Faug, T., P. Caccamo, and B. Chanut. 2011. Equation for the force experienced by a wall overflowed by a granular avalanche: Experimental verification. Physical Review 84 (051301): 1-18.

Favier, L., D. Daudon, F.V. Donzé, and J. Mazars. 2009. Predicting the drag coefficient of a granular flow using the discrete element method. Journal of Statistical Mechanics: Theory and Experiment https://doi.org/10.1088/1742-546 8/2009/06/P06012.

Fell, R., J. Corominas, Ch. Bonnard, L. Cascini, E. Leroi, and W.Z. Savage. 2008. On behalf of the JTC-1 joint technical committee on landslides and engineered slopes. Guidelines for landslide susceptibility, hazard and risk zoning for land use planning. Engineering Geology 102: 85-98.

Fredlund, D.G., N.R. Morgenstern, and R. A Widger. 1978. The shear strength of unsaturated soils. Canadian Geotechnical Journal 15: 313-321.

Fukagawa, R., K. Sako, H.H. Bui, and J.C. Wells. 2011. Slope stability analysis and discontinuous slope failure simulation by elasto-plastic smoothed particle hydrodynamics (SPH). Geotechnique 61 (7): 565-574.

Futai, M.M., W.A. Lacerda, and M.S.S. Almeida. 2004. Evolution of gully processes in unsaturated soils. In Landslides: Evaluation and Stabilization, Lacerda, Ehrlich, Fontoura \&and Sayao (eds), vol. 2, 1019-1025.

Geoslope. 2005. User's guide. GeoStudio 2004, Version 6.13. Calgary: Geo-Slope Int. Ltd.

Ghasemi, P., S. Cuomo, A. Di Perna, M. Martinelli, and M. Calvello. 2019. MPManalysis of landslide propagation observed in flume test. In Proc. of II International Conference on the Material Point Method for modelling soilwater-structure interaction. 8-10 January 2019, University of Cambridge, UK.

Ghasemi, P., M. Martinelli, S. Cuomo, and M. Calvello. 2018. MPM modelling of static liquefaction in reduced-scale slope. Numerical Methods in Geotechnical Engineering IX 2: 1041-1046.

Ghilardi, P., L. Natale, and F. Savi. 2001. Modeling debris flow propagation and deposition. Physics and Chemistry of the Earth, Part C: Solar, Terrestrial \& Planetary Science 26 (9): 651-656.

Hungr, O. 1995. A model for the runout analysis of rapid flow slides, debris flows, and avalanches. Canadian Geotechnical Journal 32: 610-623.

Hungr, O. 2004. Flow slides and flows in granular soils. In Proc. of the Int. Workshop Flows 2003 - Occurrence and Mechanisms of Flows in Natural Slopes and Earthfill, Sorrento, patron Ed.

Hungr, O., J. Corominas, and E. Eberhardt. 2005. Estimating landslide motion mechanism, travel distance and velocity. In Landslide Risk Management, 99-128.

Hungr, O., and S.G. Evans. 2004. Entrainment of debris in rock avalanches: An analysis of a long run-out mechanism. Geological Society of America Bulletin 116 (9-10): 1240-1252.

Hungr, O., S.G. Evans, M.J. Bovis, and J.N. Hutchinson. 2001. A review of the classification of landslides of the flow type. Environmental and Engineering Geoscience VII 3: 221-238.

Hungr, O., and S. McDougall. 2009. Two numerical models for landslide dynamic analysis. Computers \& Geosciences 35: 978-992.

Hutchinson, J.N. 1986. A sliding-consolidation model for flow slides. Canadian Geotechnical Journal 23: 115-126.

Iverson, R.M. 2000. Landslide triggering by rain infiltration. Water Resources Research 367: 1897-1910.
Iverson, R.M., M.E. Reid, and R.G. LaHusen. 1997. Debris flow mobilization from landslides. Annual Review of Earth and Planetary Sciences 25: 85-138.

Iverson, R.M., M.E. Reid, M. Logan, R.G. LaHusen, J.W. Godt, and J.P. Griswold. 2011. Positive feedback and momentum growth during debris-flow entrainment of wet bed sediment. Nature Geoscience 4 (2): 116.

Jaky, J. 1944. The coefficient of earth pressure at rest. Journal of the Society of Hungarian Architects and Engineers: $355-358$.

Janbu, N. 1954. Application of composite slip surface for stability analysis. In European Conference on Stability Analysis, Stockholm, Sweden.

Johnson, K.A., and N. Sitar. 1990. Hydrologic conditions leading to debris-flow initiation. Canadian Geotechnical Journal 27 (6): 789-801.

King, J.P. 2001a. The Tsing Shan debris flow and debris flood. Landslide study report LSR 2/2001. In Geotechnical Engineering Office, Civil Engineering and Development Department, The Government of the Hong Kong Special Administrative Region, Hong Kong, People's Republic of China.

King, J.P. 2001b. The 2000 Tsing Shan debris flow and debris flood. Landslide study report no. LSR 3/2001. In Geotechnical Engineering Office, Civil Engineering and Development Department, The Government of the Hong Kong Special Administrative Region, Hong Kong, People's Republic of China.

Lade, P.V. 1992. Static instability and liquefaction of loose fine sandy slopes. Journal of Geotechnical Engineering, ASCE 118 (1): 51-71.

Lambe, T.W., and R.V. Whitman. 1979. Soil mechanics, 553. York: Wiley.

Laouafa, F., and F. Darve. 2002. Modelling of slope failure by a material instability mechanism. Computers and Geotechnics 29: 301-325.

Leroueil, S. 2001. Natural slopes and cuts: Movement and failure mechanisms. Geotechnique 51 (3): 197-243.

Leroueil, S. 2004. Geotechnics of slopes before failure. Landslides: Evaluation and Stabilization, Lacerda, Ehrlich 1: 863-884 Fontoura and Sayao (eds).

Lourenco, S., K. Sassa, and H. Fukuoka. 2006. Failure process and hydrologic response of a two layer physical model: Implications for rainfall-induced landslides. Geomorphology 731-2: 115-130.

Matsushi, Y., T. Hattanji, and Y. Matsukura. 2006. Mechanisms of shallow landslides on soil-mantled hillslopes with permeable and impermeable bedrocks in the Boso peninsula, Japan. Geomorphology 76: 92-108.

Medina, V., M. Hurlimann, and A. Bateman. 2008. Application of FLATModel, a 2D finite volume code, to debris flows in the northeastern part of the Iberian Peninsula. Landslides 5: 127-142.

Merodo, J.F. M. Pastor, P. Mira, L. Tonni, M.I. Herreros, E. Gonzalez, and R. Tamagnini. 2004. Modelling of diffuse failure mechanisms of catastrophic landslides. Computer Methods in Applied Mechanics and Engineering 193 (2729): 2911-2939.

Montgomery, D.R., W.E. Dietrich, R. Torres, S. P Anderson, J.T. Heffner, and K. Loague. 1997. Piezometric response of a steep unchanneled valley to natural and applied rainfall. Water Resources Research, 33, 91-109.

Moresi, L.N., F. Dufour, and H.-B. Muhlhaus. 2002. Mantle convection modeling with viscoelastic/brittle lithosphere: Numerical methodology and plate tectonic modeling. Pure and Applied Geophysics 159 (10): 2335-2356.

Moresi, L.N., F. Dufour, and H.-B. Muhlhaus. 2003. A Lagrangian integration point finite element method for large deformation modelling of viscoelastic geomaterials. Journal of Computational Physics 184: 476-497.

Morgenstern, N.R., and V.E. Price. 1965. The analysis of the stability of general slip surfaces. Geotechnique 15 (1): 79-93.

Ng, C.W.W., W.T. Fung, C.Y. Cheuk, and L. Zhang. 2004. Influence of stress ratio and stress path on behaviour of loose decomposed granite. ASCE Journal of Geotechnical and Geoenvironmental Engineering 130 (1): 36-44.

$\mathrm{Ng}$, C.W.W., and Q. Shi. 1998. A numerical investigation of the stability of unsaturated soil slopes subjected to transient seepage. Computers and Geotechnics 22 (1): 1-28.

O'Brien, J.S., P.Y. Julien, and W.T. Fullerton. 1993. Two-dimensional water flood and mudflow simulation. Journal of Hydraulic Engineering 119 (2): 244-261.

Olivares, L., and E. Damiano. 2007. Postfailure mechanics of landslides: Laboratory investigation of Flowslides in pyroclastic soils. Journal of Geotechnical and Geoenvironmental Engineering, ASCE 1331: 51-62.

Papa, M., S. Egashira, and T. Itoh. 2004. Critical conditions of bed sediment entrainment due to debris flow. Natural Hazards and Earth System Sciences 4: 469-474.

Pastor, M., T. Blanc, M.J. Pastor, M. Sanchez, B. Haddad, P. Mira, J.A. Fernandez Merodo, M.I. Herreros, and V. Drempetic. 2007a. A SPH depth integrated model with pore pressure coupling for fast landslides and related phenomena. In International Forum on Landslides Disaster Management, ed. K. Ho and L. Li, 987-1014. 
Pastor, M., A.H.C. Chan, P. Mira, D. Manzanal, J.A. Fernández Merodo, and T. Blanc. 2011. Computational geomechanics: The heritage of Olek Zienkiewicz. International Journal for Numerical Methods in Engineering 87: 457-489.

Pastor, M., and G.B. Crosta. 2012. Landslide runout: Review of analytical/empirical models for subaerial slides, submarine slides and snow avalanche. In Numerical modelling. Software tools, material models, validation and benchmarking for selected case studies Deliverable D1.7 for SafeLand project http://www.safelandfp7.eu/results/Documents/D1.7_revised.pdf.

Pastor, M., J.A. Fernández Merodo, M.I. Herreros, P. Mira, E. González, B. Haddad, M. Quecedo, L. Tonni, and V. Drempetic. 2007b. Mathematical, constitutive and numerical Modelling of catastrophic landslides and related phenomena. Rock Mechanics and Rock Engineering 411: 85-132.

Pastor, M., J.A. Fernandez-Merodo, E. Gonzalez, P. Mira, T. Li, and X. Liu. 2004. Modelling of landslides: (I). Failure mechanisms. In Degradations and Instabilities in Geomaterials, CISM Course and Lectures No. 461, ed. F. Darve and I. Vardoulakis, 287-317. Springer-Verlag.

Pastor, M., B. Haddad, G. Sorbino, S. Cuomo, and V. Drempetic. 2009. A depth integrated coupled SPH model for flow-like landslides and related phenomena. International Journal for Numerical and Analytical Methods in Geomechanics 33 (2): 143-172.

Pastor, M., M. Quecedo, J.A. Fernández Merodo, M.I. Herreros, E. González, and P. Mira. 2002. Modelling tailing dams and mine waste dumps failures. Geotechnique LII 8: 579-592.

Pastor, M., O.C. Zienkiewicz, and A.H.C. Chan. 1990. Generalized plasticity and the modelling of soil behaviour. Int. J. Numer. And anal. Methods in Geomechanics 14: 151-190.

Pirulli, M., and M. Pastor. 2012. Numerical study on the entrainment of bed material into rapid landslides. Geotechnique 62 (11): 959-972.

Pirulli, M., and G. Sorbino. 2008. Assessing potential debris flow runout: A comparison of two simulation models. National Hazards Earth System Sciences 8: 961-971.

Quan Luna, B., A. Remaître, T.W.J. van Asch, J.P. Malet, and C.J. van Westen. 2012. Analysis of debris flow behavior with a one dimensional run-out model incorporating entrainment. Engineering Geology 128: 63-75.

Rickenmann. 2009. Empirical relationships for debris flows. National Hazards 19: 47-77.

Savage, S.B., and K. Hutter. 1991. The dynamics of avalanches of granular materials from initiation to runout. Part I: Analysis. Acta Mechanica 86 (1-4): 201-223.

Sladen, J.A., R.D. D'Hollander, and J. Krahn. 1985. The liquefaction of sands, a collapse surface approach. Canadian Geotechnical Journal 22: 564-578.

Sulsky, D., S.-J. Zhou, and H.L. Schreyer. 1995. Application of a particle-in-cell method to solid mechanics. Computer Physics Communications 87: 236-252.

Takahashi, T. 1991. Debris flows, IAHR Monograph. A.A. Balkema, Rotterdam, pp. 165.

Take, W.A., M.D. Bolton, P.C.P. Wong, and F.J. Yeung. 2004. Evaluation of landslide triggering mechanisms in model fill slopes. Landslides 1: 173-184.

Tsaparas, I., H. Rahardjo, D.G. Toll, and E.C. Leong. 2002. Controlling parameters for rainfall-induced landslides. Computers and Geotechnics 1: 1-27.

Van Asch, Th.W.J., J.P. Malet, and L.P.H. van Beek. 2006. Influence of landslide geometry and kinematic deformation to describe the liquefaction of landslides: Some theoretical considerations. Engineering Geology 88: 59-69.

Wanatowski, D., and J. Chu. 2007. Static liquefaction of sand in plane-strain. Canadian Geotechnical Journal 44 (3): 299-313.

Wanatowski, D., and J. Chu. 2012. Factors affecting pre-failure instability of sand under plane-strain conditions. Geotechnique 62 (2): 121-135.

Wang, B., P.J. Vardon, and M.A. Hicks. 2016. Investigation of retrogressive and progressive slope failure mechanisms using the material point method. Computers and Geotechnics 78: 88-98.

Wang, B., P.J. Vardon, and M.A. Hicks. 2018. Rainfall-induced slope collapse with coupled material point method. Engineering Geology 239: 1-12.

Wang, F.W., K. Sassa, and G. Wang. 2002. Mechanism of a long-runout landslide triggered by the august 1998 heavy rainfall in Fukushima prefecture, Japan. Engineering Geology 63: 169-185.

Wang, G., and K. Sassa. 2001. Factors affecting rainfall induced landslides in laboratory flume tests. Géotechnique 51: 587-600.

Wang, G., and K. Sassa. 2003. Pore-pressure generation and movement of rainfallinduced landslides: Effects of grain size and fine-particle content. Engineering Geology 69: 109-125.

Yamamuro, J.A., and P.J. Lade. 1998. Steady-state concepts and static liquefaction of silty sands. ASCE J Geotech Geoenviron Eng 1249: 868-878.
Yasufuku, N., H. Ochiai, and D. Hormdee. 2005. An empirical relationship for evaluating collapsible settlements of volcanic ash sandy soil. In Advanced experimental unsaturated soil mechanics, ed. Tarantino, Romero, and Cui, 265-272.

Zienkiewicz, O.C., A.H.C. Chan, M. Pastor, B.A. Shrefler, and T. Shiomi. 1999. Computational Geomechanics. Wiley.

Zienkiewicz, O.C., C.T. Chang, and P. Bettess. 1980. Drained, undrained, consolidating dynamic behaviour assumptions in soils. Geotechnique 30: 385-395.

\section{Publisher's Note}

Springer Nature remains neutral with regard to jurisdictional claims in published maps and institutional affiliations.

\section{Submit your manuscript to a SpringerOpen ${ }^{\circ}$ journal and benefit from:}

- Convenient online submission

- Rigorous peer review

- Open access: articles freely available online

- High visibility within the field

- Retaining the copyright to your article

Submit your next manuscript at $\boldsymbol{\nabla}$ springeropen.com 